\title{
ARTICLE
}

\section{Identification of proliferative progenitors associated with prominent postnatal growth of the pons}

\author{
Robert A. Lindquist 1,2,3, Cristina D. Guinto ${ }^{1,4}$, Jose L. Rodas-Rodriguez ${ }^{1,4}$, Luis C. Fuentealba1,4, \\ Matthew C. Tate ${ }^{1,4}$, David H. Rowitch ${ }^{1,5} \&$ Arturo Alvarez-Buylla, ${ }^{1,4}$
}

The pons controls crucial sensorimotor and autonomic functions. In humans, it grows sixfold postnatally and is a site of paediatric gliomas; however, the mechanisms of pontine growth remain poorly understood. We show that the murine pons quadruples in volume postnatally; growth is fastest during postnatal days $0-4$ (PO-P4), preceding most myelination. We identify three postnatal proliferative compartments: ventricular, midline and parenchymal. We find no evidence of postnatal neurogenesis in the pons, but each progenitor compartment produces new astroglia and oligodendroglia; the latter expand 10- to 18-fold postnatally, and are derived mostly from the parenchyma. Nearly all parenchymal progenitors at P4 are So $22^{+}$Olig2 ${ }^{+}$, but by P8 a Sox $2^{-}$subpopulation emerges, suggesting a lineage progression from Sox $2^{+}$'early' to Sox2 ${ }^{-}$'late' oligodendrocyte progenitor. Fate mapping reveals that $>90 \%$ of adult oligodendrocytes derive from P2-P3 Sox2 ${ }^{+}$progenitors. These results demonstrate the importance of postnatal Sox2 ${ }^{+}$Olig2 ${ }^{+}$progenitors in pontine growth and oligodendrogenesis.

\footnotetext{
${ }^{1}$ Eli \& Edythe Broad Center of Regeneration Medicine and Stem Cell Research, University of California-San Francisco, San Francisco, California 94143 , USA. ${ }^{2}$ Medical Scientist Training Program, University of California-San Francisco, San Francisco, California 94143, USA. ${ }^{3}$ Neuroscience Graduate Program, University of California-San Francisco, San Francisco, California 94143, USA. ${ }^{4}$ Department of Neurological Surgery, University of California-San Francisco, San Francisco, California 94143, USA. ${ }^{5}$ Department of Pediatrics, University of California-San Francisco, San Francisco, California 94143 , USA.

Correspondence and requests for materials should be addressed to A.A.-B. (email: AlvarezBuyllaA@ucsf.edu).
} 
T he mammalian brain undergoes significant postnatal growth. Postnatal growth could aid experience-dependent acquisition of brain function ${ }^{1}$, and may confer susceptibility to tumorigenesis ${ }^{2}$. The human pons is a site of exceptional postnatal growth ${ }^{3}$ and lethal paediatric gliomas; however, knowledge of the cells responsible for pons growth remains limited. One study suggested a 'second peak' of Nestin ${ }^{+}$ progenitor cells in ventral human pons at 7 years ${ }^{5}$, though a subsequent study did not find evidence to support that claim, and instead observed that such progenitors were restricted to infancy ${ }^{3}$. The nature of postnatal pontine progenitor cells has consequences for pontine gliomagenesis, and for the normal postnatal development and function of this crucial brain region.

The dorsal pons (tegmentum) contains autonomic nuclei controlling awakeness and arousal ${ }^{6}$, respiration ${ }^{7}$ and adrenergic tone ${ }^{8}$, as well as cranial nerves and nuclei mediating facial sensation and motion?. The ventral pons (basis pontis) contributes to motor function, in part as a 'bridge' between cortex and cerebellum: neurons in the pontine grey nuclei receive synapses from cortex and project to cerebellum via the middle cerebellar peduncle ${ }^{10}$. Interestingly, among primates the size of the basis pontis scales directly with the size of the neocortex ${ }^{11}$. The basis pontis also contains the corticospinal tract, whose descending axons carry motor signals from cortex to spinal motor neurons. Many pontine circuits serve functions that are postnatally acquired or refined, but nearly all studies of pons development have focused on prenatal events, beginning with its embryonic derivation from various segments of the rhombencephalon. Pontine neurogenesis occurs prenatally ${ }^{12-17}$ : autonomic nuclei and cranial nerves (V-VIII) derive mainly from rhombomeres 2 to 5 (refs 18,19), though some tegmental neurons derive from rhombomere 1 (ref. 20); the neurons of the basis pontis are born in rhombomeres $6-8$ and migrate anteriorly to form the pontine grey nuclei in the territory of rhombomeres 3-4 (refs 20,21). Proliferation ${ }^{22}$ and gliogenesis ${ }^{23-26}$ have been documented in embryonic murine and avian pons, but the question of which cells are responsible for postnatal pontine growth remains unanswered.

Here we show that as in humans, the postnatal mouse basis pontis grows more than tegmentum, with growth comparable to rapidly growing forebrain structures; growth is fastest at birth and mostly occurs before P16. Postnatal progenitor cells in the pons are found (1) in the ventricular zone along the ventral walls of the fourth ventricle, (2) in the midline domain and (3) in the parenchyma. Progenitors proliferate in a single wave peaking at postnatal day 4 . We observe that proliferative Olig2 ${ }^{+}$progenitors include an unexpected and abundant Sox $2^{+}$subpopulation, which is enriched in basis pontis. Remarkably, postnatal Sox ${ }^{+}$ progenitor cells produce more than $90 \%$ of adult mouse pons oligodendrocytes, contributing to a 10- to 18 -fold postnatal expansion of the oligodendroglial lineage.

\section{Results}

Postnatal pontine growth rates are fastest from P0 to P4. The human pons grows sixfold from birth to adulthood ${ }^{3}$. To measure the postnatal growth of the mouse pons, we prepared CD1 wildtype mouse tissue for sectioning in a plane containing basis pontis, tegmentum and fourth ventricle (Fig. 1a and Methods section). We computed volumes of basis pontis and tegmentum based on areas measured in every second section through the pons (Fig. 1b-d). The basis pontis grew fivefold postnatally, from $0.38 \mathrm{~mm}^{3}$ at birth to $1.96 \mathrm{~mm}^{3}$ in adulthood (Fig. 1c), while the pontine tegmentum grew fourfold, from $2.48 \mathrm{~mm}^{3}$ to $10.3 \mathrm{~mm}^{3}$ (Fig. 1d). This growth was comparable to the four- to fivefold postnatal increase in mouse hippocampal and neocortical volume measured by magnetic resonance imaging ${ }^{27}$ and histologic methods $^{28}$, and greater than the two- to threefold postnatal increase in volume of anterior thalamic nuclei ${ }^{28}$. The absolute volumetric growth rate $\left(\mathrm{mm}^{3}\right.$ per day) was greater in tegmentum than in basis pontis, due to the tegmentum's larger size, and in tegmentum the absolute rate of growth was greatest during P4-P10 (Fig. 1e). However, the daily per cent increase in volume was greatest during P0-P4, and was greater in basis pontis than tegmentum during that period, with basis pontis growing at an average rate of $16 \%$ daily (Fig. 1f). The rate of growth then declined gradually through weaning age. The size of the pons at P24 was not significantly different from that in adults aged P64 $(P>0.2$, unpaired $t$-test). These data indicate that the mouse pons grows rapidly during early postnatal life and proportionally more in basis pontis than tegmentum.

Myelination does not account for pontine growth from P0 to P4. The rapid early postnatal growth of human basis pontis is attributable in part to myelination ${ }^{3}$. To determine whether myelination accounted for the rapid early growth of the postnatal mouse basis pontis, we performed immunohistochemistry for myelin basic protein (MBP). The distribution of MBP in pontine sections of increasing age is shown in Fig. 2a-c. MBP appeared in concert with adenomatous polyposis coli (APC), a marker of mature oligodendrocytes, first in selected white matter tracts of tegmentum, for example, medial longitudinal fasciculus and trigeminal nerve $(\mathrm{V})$ by P2-P4, followed by white matter of basis pontis from P8 to P10 and grey matter of basis pontis and tegmentum by P8 to P12 (Fig. 2d). The extent of myelination and the apparent thickness of myelinated tracts increased throughout the pons between P10 and P24 (Fig. 2c,d). The progression of myelination evidenced by MBP staining is consistent with a magnetic resonance imaging study on the development of 12 selected white matter tracts in postnatal mouse brain (including three brainstem tracts ${ }^{27}$. Interestingly, while our data show that the pons underwent its most rapid growth before P4, hardly any MBP fibres were observed in P4 basis pontis (Fig. 2b,d). This suggests that, in contrast to human, the mouse pons shows rapid early postnatal growth before extensive addition of myelin.

Proliferation occurs in three germinal zones and peaks at $\mathbf{P 4}$. On the basis of the findings above, we hypothesized that early postnatal pontine growth could be due to proliferation of neuronal and/or glial precursor cells. To measure proliferation in postnatal development, we injected an age series of CD1 wildtype mice with a single dose of the thymidine analogue BrdU, $100 \mathrm{~min}$ before perfusion (Fig. 3a). Immunostaining revealed $\mathrm{BrdU}^{+}$cells throughout the mouse brainstem (Fig. 3b,c); the density of $\mathrm{BrdU}^{+}$cells was greater in basis pontis than in any other region of the brainstem (Fig. 3d,h; Supplementary Fig. 3f,g), and also greater in the pontine tegmentum relative to midbrain tegmentum (Supplementary Fig. 3h). We observed three main anatomical compartments of $\mathrm{BrdU}^{+}$cells: (1) along the ventral surface of the fourth ventricle (ventricular zone, 'VZ'); (2) along the midline; and (3) within parenchyma (Fig. 3e). In all three compartments, the density of $\mathrm{BrdU}^{+}$cells was greatest at $\mathrm{P} 4$ (Fig. 3f-h), coinciding with the period of fastest pons growth (Fig. 1e,f). Notably, in the parenchymal compartment, $\mathrm{BrdU}^{+}$ cells were denser in the basis pontis than in the tegmentum (Fig. 3h). This greater proliferation in basis pontis coincides with its larger daily per cent increase in volume (Fig. 1f). Basis pontis proliferation peaked at $276 \pm 15$ cells per $\mathrm{mm}^{2}$ at $\mathrm{P} 4$, and at P12 was still more than half its P4 peak, while tegmentum proliferation peaked at $196 \pm 39$ cells per $\mathrm{mm}^{2}$ at $\mathrm{P} 4$, and declined more than $50 \%$ by P12 (Fig. 3h). Similarly, proliferation in VZ and midline peaked at $\mathrm{P} 4$ with $40.6 \pm 3.1$ and $16.3 \pm 3.7$ cells per 
a

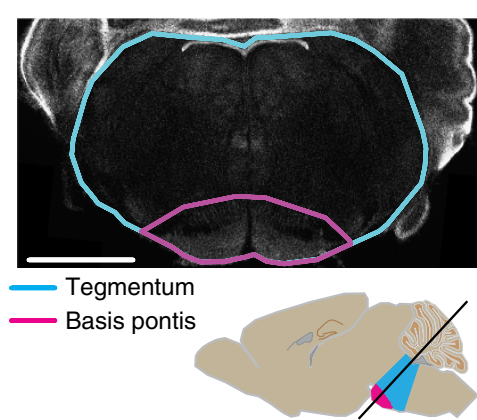

C

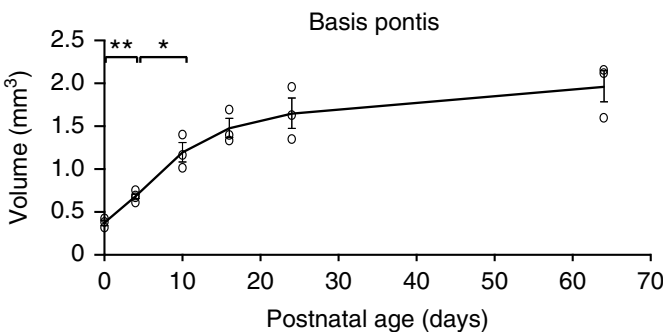

e

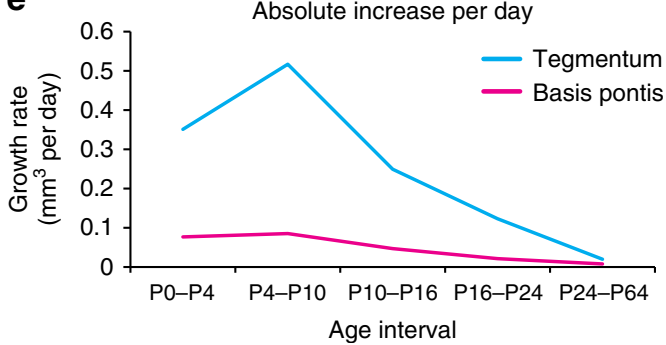

b Po

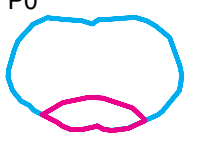

10 sections

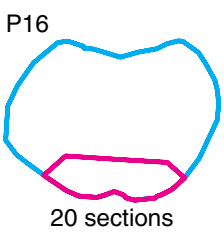

$\mathrm{P4}$

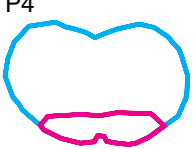

14 sections

$\mathrm{P} 24$

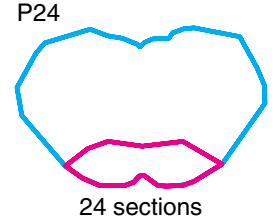

P10

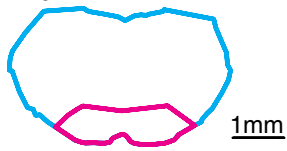

18 sections

P64

d

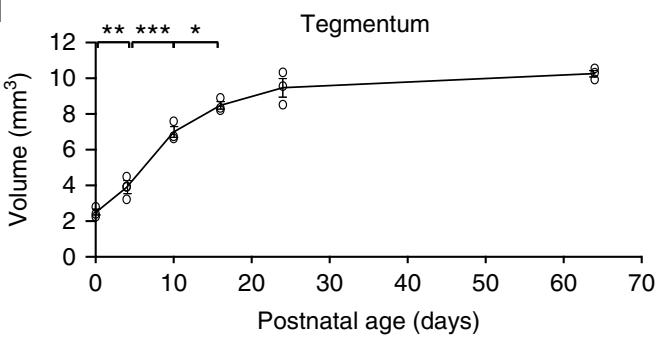

f

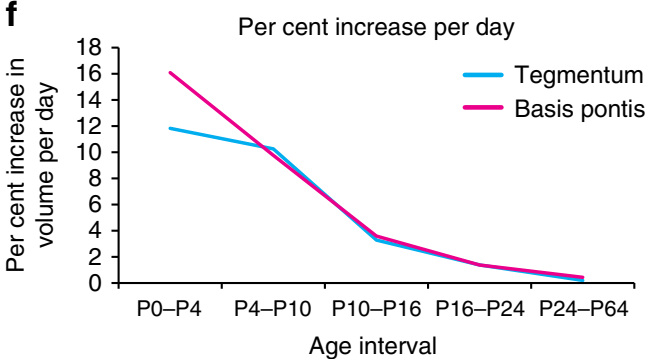

Figure 1 | Postnatal growth of mouse pons. (a) DAPI stain of PO mouse pons section containing tegmentum (cyan) and basis (magenta), sectioned at oblique angle normal to axis of spinal cord (inset). Basis pontis includes pontine nuclei and adjacent white matter tracts (transversus fasciculus pontis, longitudinalis fasciculus pontis, and middle cerebral peduncle ventral to pontine nuclei). Scale bar $=1 \mathrm{~mm}$. (b) Postnatal growth of pons in dorsal-ventral and medial-lateral axes is illustrated by section tracings as in (a); growth along rostral-caudal axis is indicated by the number of sections passing through pons. Scale bar $=1 \mathrm{~mm}$. (c,d) Volumes of pons regions were computed by summation of areas measured in every second section through pons, times distance between measured sections $(100 \mu \mathrm{m})$. Graphs show individual replicates with mean \pm s.e.m., $n \geq 3$ mice per timepoint. Unpaired $t$-test revealed significant differences between the following consecutive timepoints: P0 and P4 (both regions), P4 and P10 (both regions), and P10 and P16 (tegmentum). ${ }^{\star} P<0.05,{ }^{\star \star} P<0.01,{ }^{\star \star} P<0.001$. (e) Absolute increase in volume per day computed as (mean volume at end of interval- mean volume at beginning of interval) $\div$ (number of days in interval). (f) Per cent increase in volume per day computed as ( $100 \times(($ mean volume at end of interval $\div$ mean volume at beginning of interval) $\left.{ }^{(1 / \text { number of days in interval) }}-1\right)$ ).

$\mathrm{mm}$, respectively, and declined more than $50 \%$ by $\mathrm{P} 8$ and $\mathrm{P} 12$, respectively (Fig. 3f,g). There was a significant increase in proliferation density from $\mathrm{P} 0$ to $\mathrm{P} 4$ in $\mathrm{VZ}(P=0.0302$, unpaired $t$-test) and basis pontis $(P=0.0072)$, while in tegmentum and midline the increased density of $\mathrm{BrdU}^{+}$cells from $\mathrm{P} 0$ to $\mathrm{P} 4$ was not statistically significant ( $P=0.128$ and $P=0.121$, respectively). Parenchymal proliferation declined by P20 to $<10 \%$ of its P4 peak, and in adulthood (P64) amounted to $1.5 \%$ of its $\mathrm{P} 4$ peak (Fig. 3h). VZ proliferation declined sooner, reaching $<10 \%$ of its P4 peak by $\mathrm{P} 12$ and $1.5 \%$ of its P4 peak by P20 (Fig. $3 \mathrm{f}$ ). We observed no BrdU ${ }^{+} \mathrm{VZ}$ cells at P28 or above. These findings show that the pons is the most proliferative postnatal brainstem region; its cell proliferation shows a single postnatal peak, at $\mathrm{P} 4$, coincident with the period of fastest growth. These data also show that proliferation declines at different rates in pontine $\mathrm{VZ}$, parenchyma, and midline, and at different levels of the brainstem.

Neurogenesis does not occur in the postnatal pons. The birthdating studies of Altman and Bayer ${ }^{12-17}$ indicate that neurons of the rat pons are primarily born before birth.
However, it is not known if some pontine neurons are born postnatally in mouse. Given the dramatic postnatal growth (Fig. 1) and the presence of some migrating precerebellar neurons entering the pontine grey nuclei as late as P0 (ref. 29), it was possible that some pontine neurons could be born postnatally. We delivered BrdU in a single dose to wild-type mice aged P0 or P4. Analysis at P28 revealed no $\mathrm{BrdU}^{+} \mathrm{NeuN}^{+}$cells in either basis pontis or tegmentum; since this BrdU dosage regimen might have been insufficient to identify slowly or rarely dividing cells, we administered BrdU or EdU every $12 \mathrm{~h}$ over a 4 -day course spanning ages P1-P4, P5-P8 (Supplementary Fig. 4a), P9-P12 and so on through P29-P32, followed by 28-day chase periods. (The use of EdU in fate mapping may have reduced survival of EdU-labelled cells on a second cell cycle post labelling ${ }^{30,31}$, but would not have affected cells undergoing a single cell cycle.) Many cells retained BrdU and/or EdU after 28-day chase, including some glial fibrillary acidic protein (GFAP) ${ }^{+}$astrocytes and $\mathrm{APC}^{+}$oligodendrocytes (Supplementary Fig. 4b,c); yet we observed no EdU ${ }^{+} \mathrm{NeuN}^{+}$or BrdU ${ }^{+} \mathrm{NeuN}^{+}$cells in the pons (Supplementary Fig. 4d). Finally, we performed co-staining of the 

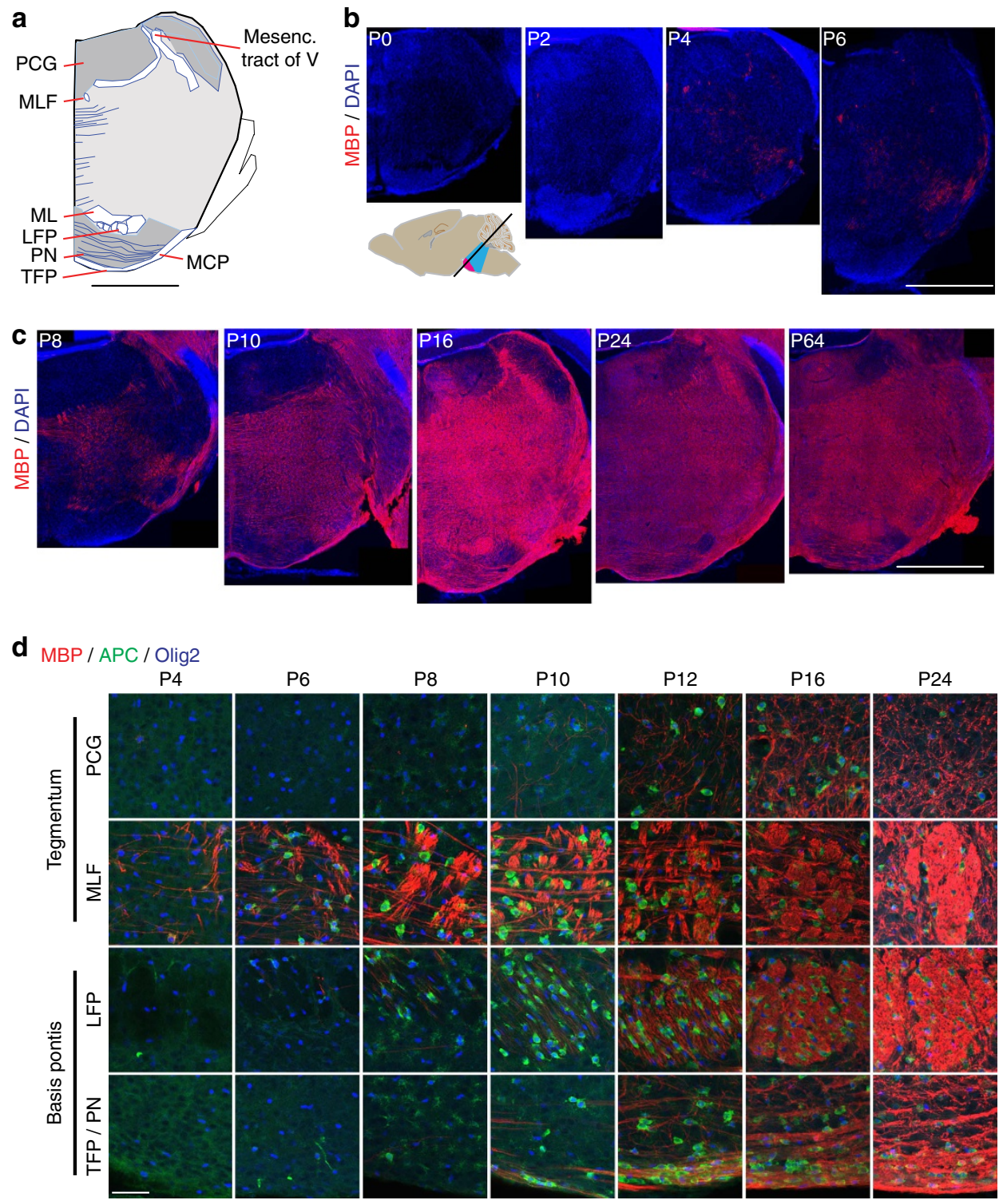

Figure 2 | Progressive myelination in pons. (a) P16 pons section stained for myelin basic protein (MBP) was traced to highlight landmark tracts and grey/white regions. Lines indicate thick fibres within grey matter regions. (b,c) MBP-stained pons hemisections at indicated ages; red, MBP; blue, DAPI. Scale bar for $(\mathbf{a}-\mathbf{c})=1 \mathrm{~mm}$. (d) High-resolution images of representative pons regions, including both grey and white matter within tegmentum and basis, illustrate differently timed regional onsets of myelination and progressive increase over postnatal development. Red, MBP; green, APC; blue, Olig2. Scale bar, $50 \mu \mathrm{m}$. LFP, longitudinal fasciculus pontis; MCP, middle cerebellar peduncle; ML, medial lemniscus; MLF, medial longitudinal fasciculus; PCG, pontine central grey; PN, pontine nuclei; TFP, transverse fasciculus pontis.

neuroblast markers doublecortin (DCX) and PSA-NCAM with BrdU in mice aged P0, P4, P8... through P32, each perfused 100 min after a single dose of BrdU, and found no colocalization of BrdU with either DCX or PSA-NCAM (Supplementary Fig. 4e,f). Altogether, these results indicate that pontine neurons are not born postnatally in mice, and thus neurogenesis does not account for postnatal pontine growth.

Postnatal expansion of the oligodendroglial lineage. Because the pons lacks postnatal neurogenesis and undergoes delayed but extensive myelination, we hypothesized that pons growth may coincide with an increase in oligodendroglia. To count the oligodendroglial population in the developing postnatal pons, we performed stereologic analysis of wild-type tissue sections co-stained for Sox10, Olig2 and APC (Fig. 4a-f). Oligodendrocyte precursor cells (OLPs) were defined as Sox $10^{+} \mathrm{Olig} 2^{+} \mathrm{APC}^{-}$; oligodendrocytes (OLs) were defined as $\mathrm{APC}^{+}$cells coexpressing Sox10, Olig2 or both (Fig. 4a). At birth, the basis pontis contained $6,357 \pm 610$ OLPs, increasing to $13,688 \pm 790$ OLPs by P4 and $29,527 \pm 922$ by P10; OLPs peaked at P16 at 35,369 $\pm 5,808$, and declined by P24 to $10,372 \pm 2,004$ (Fig. $4 \mathrm{~d}$ ). The number of mature OLs in basis pontis increased markedly from $958 \pm 212$ at $\mathrm{P} 4$ to $26,119 \pm 2,666$ at $\mathrm{P} 10$ and $88,750 \pm 11,417$ at P16, after which the number of mature OLs in basis pontis remained constant to adulthood (Fig. 4d). The tegmentum underwent similar phases: the number of OLs in tegmentum was $19,990 \pm 2,612$ at P4, increasing to $214,996 \pm 49,232$ by P10 and $443,480 \pm 35,041$ by P16 (Fig. 4e). The density of OLPs and morphology of APC staining changed markedly through postnatal development (Fig. 4c), reflecting the progressive increase and maturation of oligodendroglia through three phases: OLP expansion without differentiation ( $\mathrm{P} 0-\mathrm{P} 4)$, OLP expansion and 

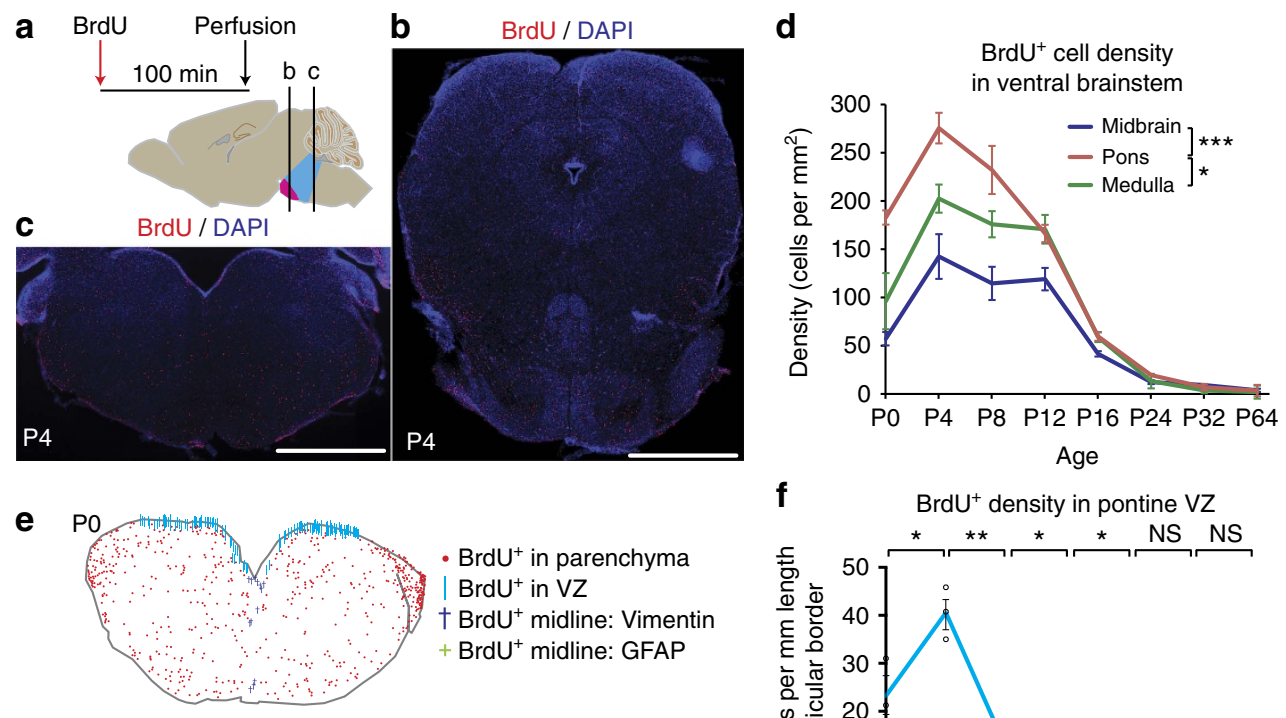

- BrdU ${ }^{+}$in parenchyma $\mathrm{BrdU}^{+}$in $\mathrm{VZ}$

$\dagger \mathrm{BrdU}^{+}$midline: Vimentin $-\mathrm{BrdU}^{+}$midline: GFAP
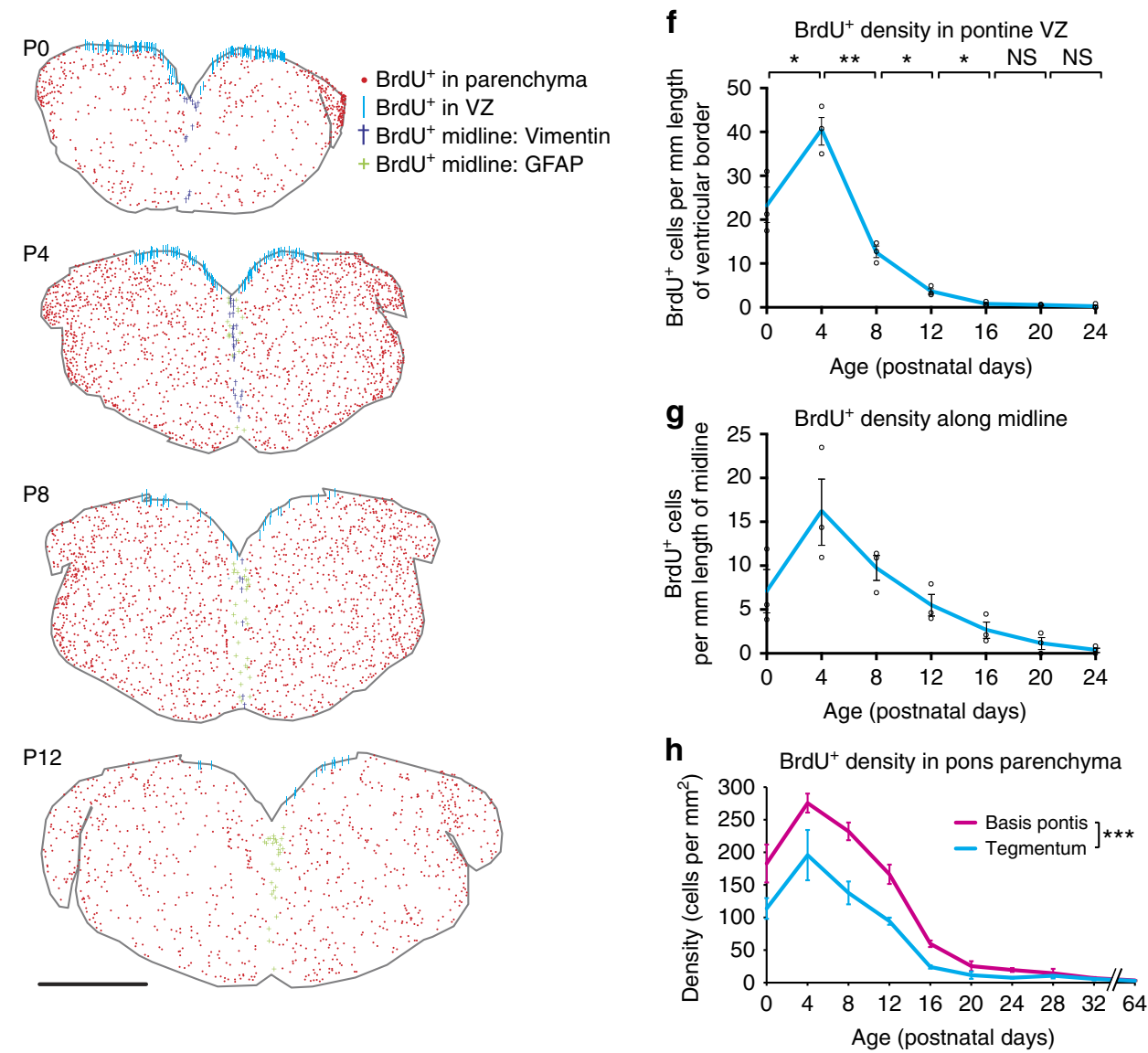

Figure 3 | BrdU reveals three compartments of pontine proliferation. (a) CD1 wild-type mice were given a single dose of BrdU by intraperitoneal injection (50 $\left.\mathrm{mg} \mathrm{kg}^{-1}\right) 100 \mathrm{~min}$ before perfusion, thereby labelling acutely proliferative cells. Standard coronal sections indicate levels of basis pontis (b) and pontine 4th VZ (c). (b,c) DAPI and BrdU costains at levels shown in (a) reveal proliferation throughout the mouse brainstem, but concentrated in basis pontis (b) and along 4th ventricle $(\mathbf{c})$. Scale bar, $1 \mathrm{~mm}$. (d) Density of BrdU + cells is greater in basis pontis (ventral pons) than in ventral midbrain $\left(F_{1,32}=78.16\right.$, $P<0.0006)$ or ventral medulla $\left(F_{1,32}=11.53, P=0.0108\right.$; regional comparisons by two-way ANOVA and Bonferroni post hoc adjustment; graph shows mean \pm s.e.m., $n=3$ mice per timepoint). See Supplementary Fig. 3 for dorsal brainstem regions. (e) Representative sections at level of (c) traced in Stereolnvestigator software. Each mark represents one BrdU ${ }^{+}$nucleus. Cyan marks represent BrdU ${ }^{+}$cells in VZ, which was defined by the density of DAPI along the 4th ventricle; midline populations were defined by contact with vimentin (dark blue) or GFAP (green) fibres that contacted the midline glial structure; all other BrdU ${ }^{+}$nuclei were considered parenchymal and labelled red. Scale bar, $1 \mathrm{~mm}$. (f) Density of proliferative cells along pontine $\mathrm{VZ}$; graph shows individual replicates with mean \pm s.e.m. ( $n=3$ mice per timepoint); comparisons are by unpaired $t$-test. ( $(\mathbf{g})$ Density of BrdU ${ }^{+}$cells along midline; graph shows individual replicate values with mean \pm s.e.m. ( $n=3$ mice per timepoint). (h) Density of BrdU ${ }^{+}$cells is greater in basis pontis than pontine tegmentum $\left(F_{1,40}=39.06, P<0.0006\right.$; regional comparisons by two-way ANOVA and Bonferroni post hoc adjustment; graph shows mean \pm s.e.m., $n=3$ mice per timepoint). ${ }^{\star} P<0.05 ;{ }^{\star \star} P<0.01,{ }^{\star \star *} P<0.001$. NS, not significant.

differentiation to OLs (P4-P16), and OLP decline (P16-P24). Between P0 and P16, the oligo-lineage population increased 18 -fold in basis pontis and 10 -fold in tegmentum (Fig. 4f). The stereologic count of oligodendroglia, therefore, revealed a marked postnatal increase in oligodendroglia, and raised the question of which progenitor domains give rise to these new cells.
Postnatal VZ and midline domains add few cells to parenchyma. Co-immunostaining for BrdU and intermediate filaments revealed proliferative progenitors associated with $\mathrm{GFAP}^{+}$and Vimentin ${ }^{+}$fibres in the postnatal VZ and midline domains (Figs $5 \mathrm{a}$ and $6 \mathrm{a}, \mathrm{b})$. Both VZ and midline also contained Nestin ${ }^{+}$ cells at P4 (Supplementary Fig. 5), and a subpopulation of VZ 
a

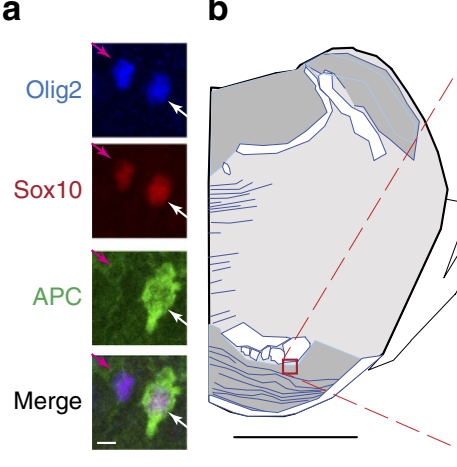

d

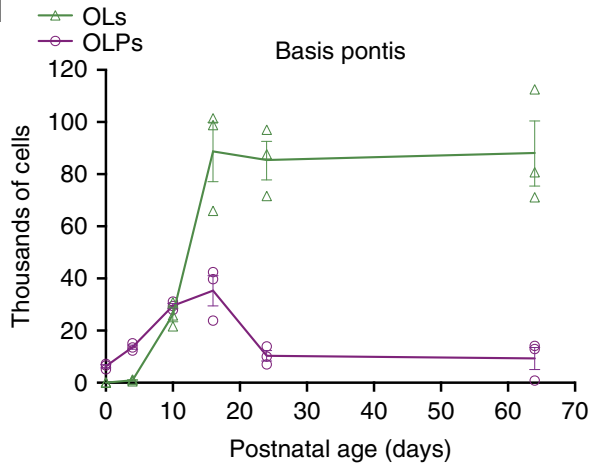

f

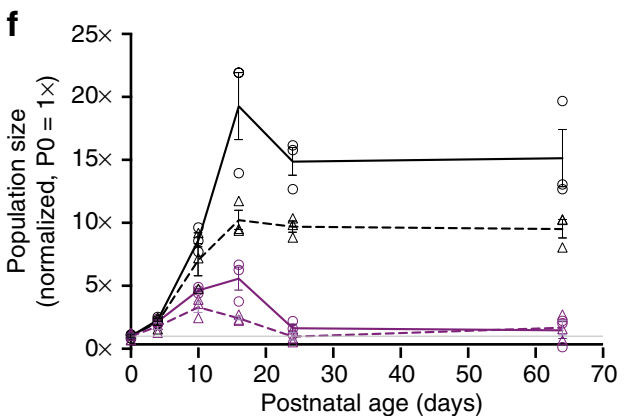

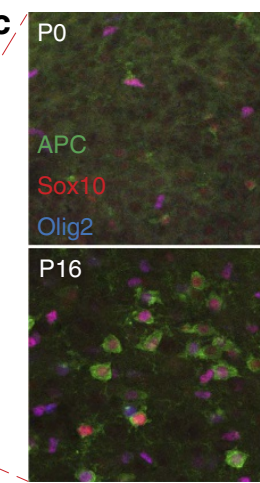
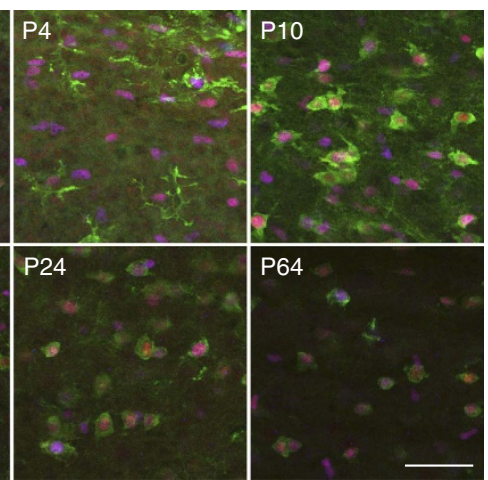

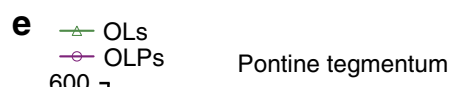

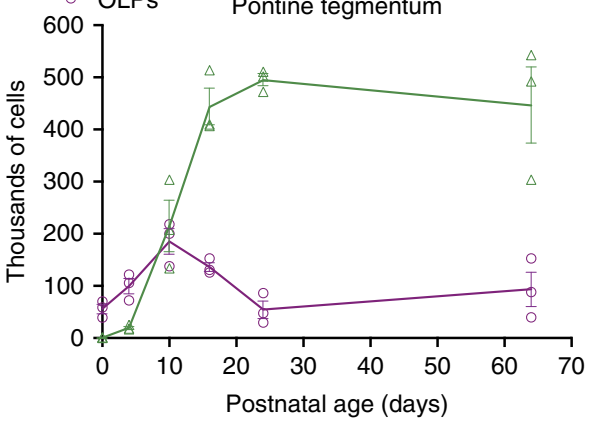

$\multimap$ Basis pontis total (OLs + OLPs)

$-A-$ Tegmentum total (OLs + OLPs)

$\rightarrow$ Basis pontis OLPS

$-₫-$ Tegmentum OLPs

Figure 4 | Expansion and maturation of OL lineage in postnatal pons. CD1 wild-type mouse pons sections were stained for Sox10, Olig2 and APC. (a) Representative OLP (Olig2 ${ }^{+}$Sox $10^{+} \mathrm{APC}^{-}$, magenta arrow) and $\mathrm{OL}$ (Olig2 ${ }^{+}$Sox $10^{+} \mathrm{APC}^{+}$, white arrow) from $\mathrm{P} 10$ mouse basis pontis. Scale bar, $5 \mu \mathrm{m}$. (b) Schematic of basis pontis region shown at several ages in (c). Scale bar, $1 \mathrm{~mm}$. (c) Age series from basis pontis shows postnatal changes in density and maturation state of OLPs and OLs. Note sequential upregulation, condensation, and diminution of APC over time. Scale bar, $50 \mu \mathrm{m}$. (d,e) Stereologic counts of pons oligodendroglia in basis pontis (d) and tegmentum (e) over postnatal development, measured by Optical Fractionator probe in Stereolnvestigator software. Cells were identified as OLs if they expressed APC and either or both of Sox10/Olig2; cells were counted as OLPs if they expressed both Sox10 and Olig2 but not APC. (f) Counts of OLPs (purple) and total oligodendroglia (OLs + OLPs, black) were normalized to PO values, revealing fold expansion of the oligodendroglial population since PO $(1 \times)$. All graphs show individual replicates with mean \pm s.e.m. of $n=3$ mice per timepoint.

progenitors at M-phase showed phospho-Ser55-Vimentin staining in cells with radial glial-like morphology (Fig. 5b). The presence of proliferative cells and progenitor markers led us to ask whether these domains contribute new cells, and particularly oligodendroglia, to the growing pons parenchyma. We performed viral fate mapping of $\mathrm{VZ}$ progenitors by delivering adenoviral Cre into the lateral ventricles of P1 Ai14 or Ai14;ALDH1L1:GFP mice $^{32,33}$, thereby labelling $\mathrm{VZ}$ cells throughout the entire ventricular system (including fourth ventricle) with the TdTomato red fluorescent protein (Fig. $5 \mathrm{c}-\mathrm{e}$ ), and labelling also a small number of tegmental ALDH1L1:GFP ${ }^{+}$astrocytes and Sox $10^{+}$oligodendroglia (Fig. 5e-i). We performed a similar labelling of mitotic, Nestin ${ }^{+} \mathrm{VZ}$ progenitors by delivering RCAS:GFP retrovirus to the lateral ventricles of $\mathrm{P} 2$ mice carrying the Nestin-tva allele ${ }^{34}$, and again observed a small number of tegmental oligodendroglia close to the fourth ventricle (Supplementary Fig. 6). To label the midline domain, we used the FoxA2CreER driver ${ }^{35}$ crossed to the Ai14 reporter, and observed TdTomato expression in midline glial fibres as well as a small subpopulation of nearby astroglia and oligodendroglia (Fig. 6c-g). Altogether, these experiments showed that while both $\mathrm{VZ}$ and midline domains produced both oligodendroglia and astroglia, their parenchymal progeny were few in number and remained close to $\mathrm{VZ}$ or midline.

OLPs are the most proliferative population in postnatal pons. We turned our attention to the parenchymal progenitors, the largest progenitor pool in the postnatal pons. Again using BrdU to label proliferative cells 100 min before perfusion, we used mice carrying cell type-specific reporter transgenes to determine 

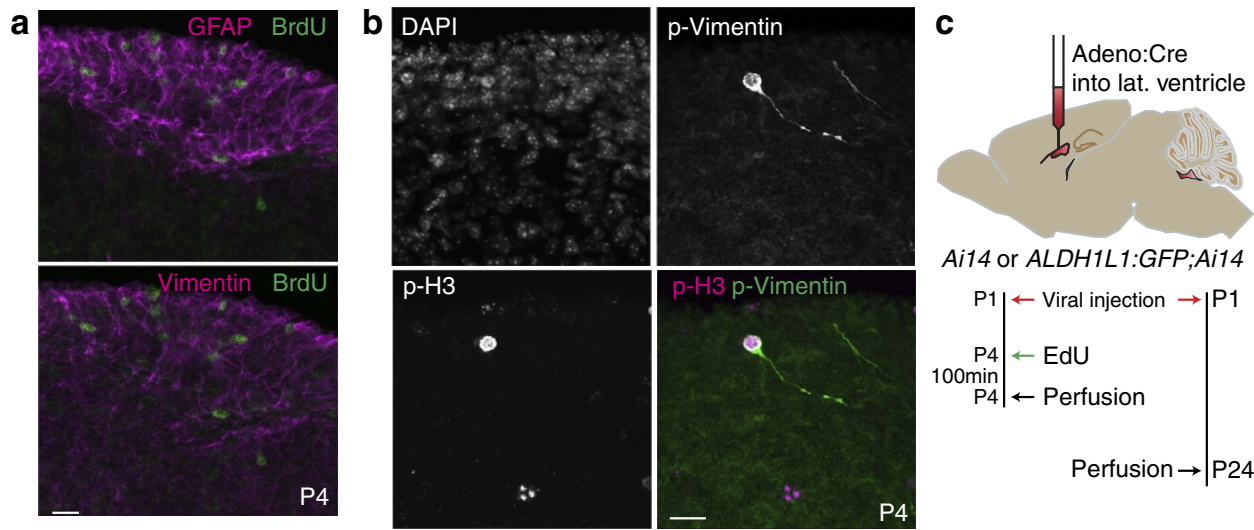

Ai14 or ALDH1L1:GFP;Ai14
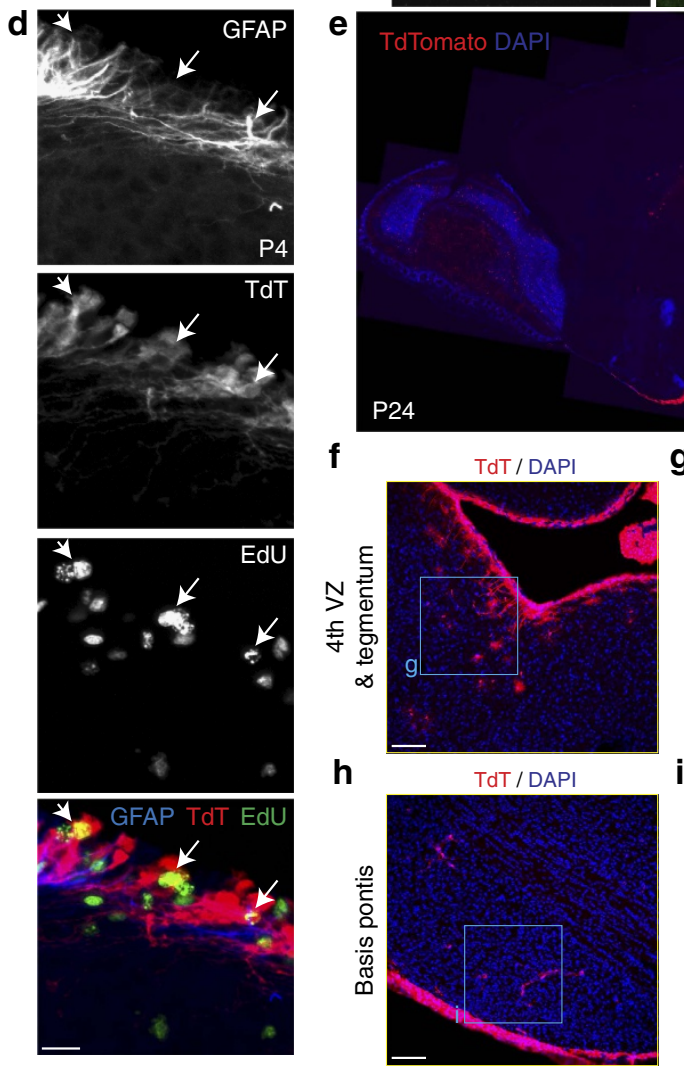

24
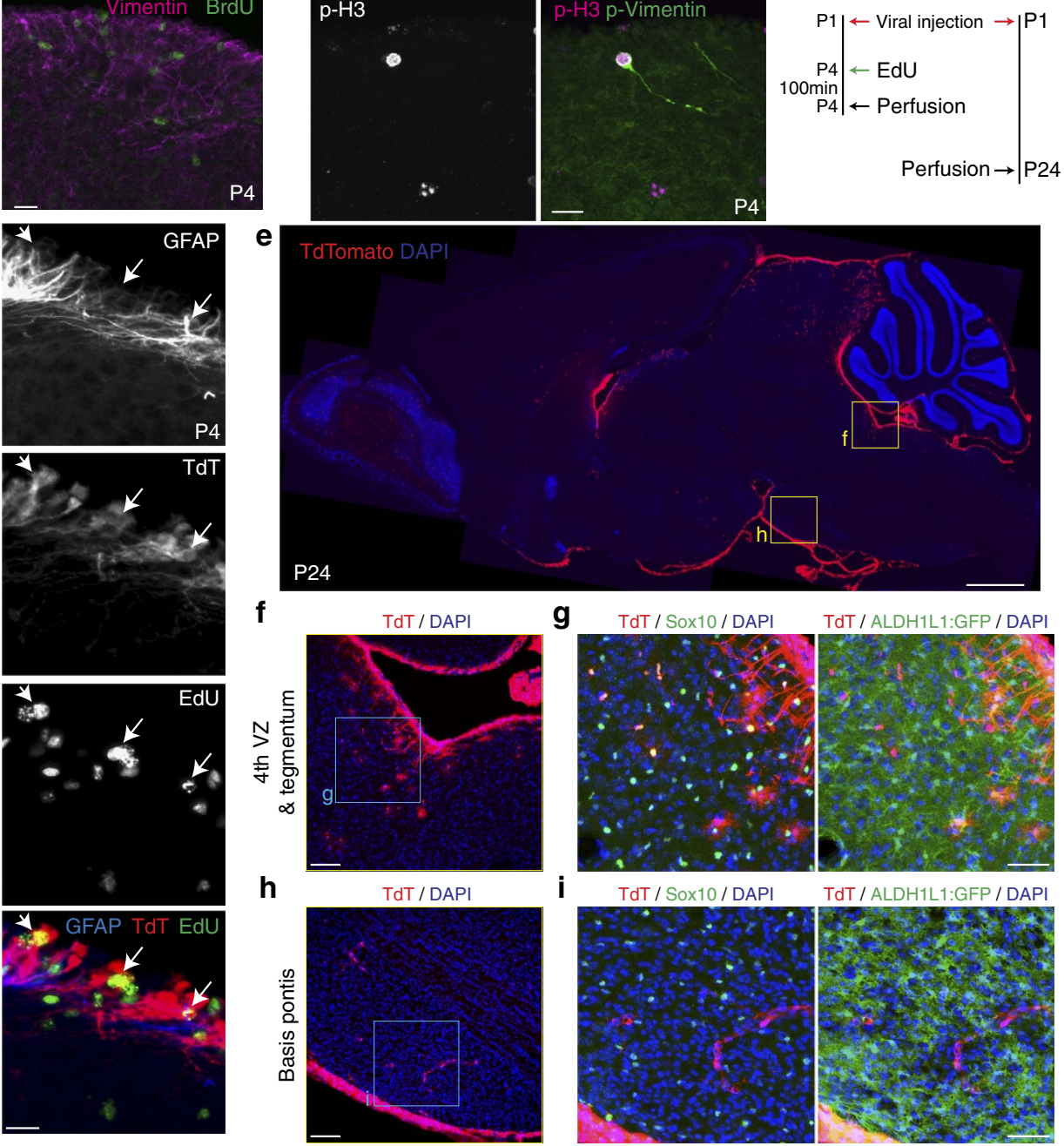

Figure 5 | Properties and progeny of postnatal fourth VZ progenitor cells. (a) Wild-type mice received BrdU in a single dose 100 min before perfusion. $\mathrm{BrdU}^{+}$nuclei in postnatal 4th VZ are surrounded by fibres of GFAP and vimentin. Scale bar, $20 \mu \mathrm{m}$. (b) Co-staining for M-phase marker phospho-histone$\mathrm{H} 3(\mathrm{pH} 3)$ and phospho-ser55-Vimentin ( $\mathrm{p}$-Vimentin) reveals radial glial-like morphology of 4 th VZ progenitors. Scale bar, $20 \mu \mathrm{m}$. (c-i) Viral fate mapping of postnatal 4th VZ progenitors. Ai14 or Ai14;ALDH1L1:GFP pups received Adeno-Cre viral injection in lateral ventricle at age P1, and were perfused at P4 (100 min after a single dose of EdU) or at P24. (d) Co-staining of P4 tissue sections for EdU, GFAP, and TdTomato reveals proliferative TdT ${ }^{+}$nuclei in the VZ of the 4th ventricle. Scale bar, $20 \mu \mathrm{m}$. (e) Cre-recombined cells are visible in olfactory bulb, confirming successful targeting of forebrain V-SVZ progenitors; along the surface of the entire ventricular system, including pontine 4th ventricle; and along the ventral surface of the brain, suggesting viral outflow to meningeal space via cisterna magna. Scale bar, $1 \mathrm{~mm}$. (f) Enlarged view of 4 th $\mathrm{VZ}$ and pontine tegmentum region indicated in (e), revealing parenchymal TdTomato $(\mathrm{TdT})^{+}$cells. Scale bar, $100 \mu \mathrm{m}$. (g) Further enlargment of pontine tegmentum as indicated in (f), showing co-immunostaining for TdTomato (Red) and lineage-specific markers (Green: left, Sox10; right, ALDH1L1:GFP). Scale bar, $50 \mu \mathrm{m}$. (h) Enlarged view of basis pontis region indicated in (e), revealing parenchymal $\mathrm{TdT}^{+}$cells. Scale bar, $100 \mu \mathrm{m}$. (i) Further enlargment of basis pontis as indicated in $\mathbf{h}$, showing immunostaining for TdT and lack of colocalization with either Sox10 (left) or ALDH1L1:GFP (right). Many TdT ${ }^{+}$cells are found along structures morphologically consistent with blood vessels. Scale bar, $50 \mu \mathrm{m}$.

the identity of proliferative cells (Fig. 7a). NG2:DsRed mice report DsRed in NG2-expressing cells, including OLPs and pericytes ${ }^{36}$, so we co-stained for Sox 10 and identified OLPs as $\mathrm{BrdU}^{+} \mathrm{DsRed}^{+}$Sox $10^{+}$triple-positive cells (Fig. $7 \mathrm{~b}$ ). ALDH1L1:GFP mice report GFP in astrocytes ${ }^{32}$, and proliferative parenchymal astrocytes were vimentin ${ }^{+}$as well (Fig. 7c). It was difficult to colocalize nuclear and filamentous markers, so we identified proliferative astrocytes as $\mathrm{BrdU}^{+} \mathrm{ALDH} 1 \mathrm{L1}: \mathrm{GFP}^{+}$ cells. Co-staining for Olig2 generally revealed segregation from astrocytes (Fig. 8g, Supplementary Fig. 7b); however, a small subpopulation of $\mathrm{BrdU}^{+} \mathrm{ALDH1L1:GFP}{ }^{+} \mathrm{Olig}^{+}{ }^{+}$astrocytes was also identified (Fig. 8h, Supplementary Fig. 7c). We measured proliferation among these cell types through postnatal development and found that proliferative OLPs outnumbered 

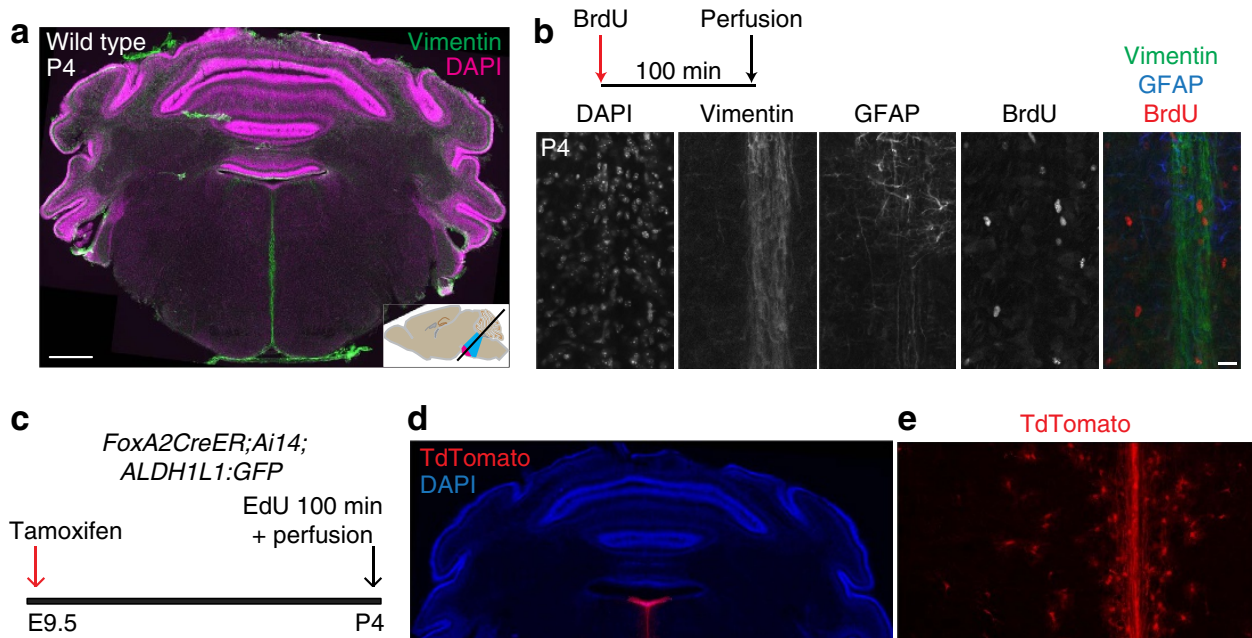

d

e TdTomato
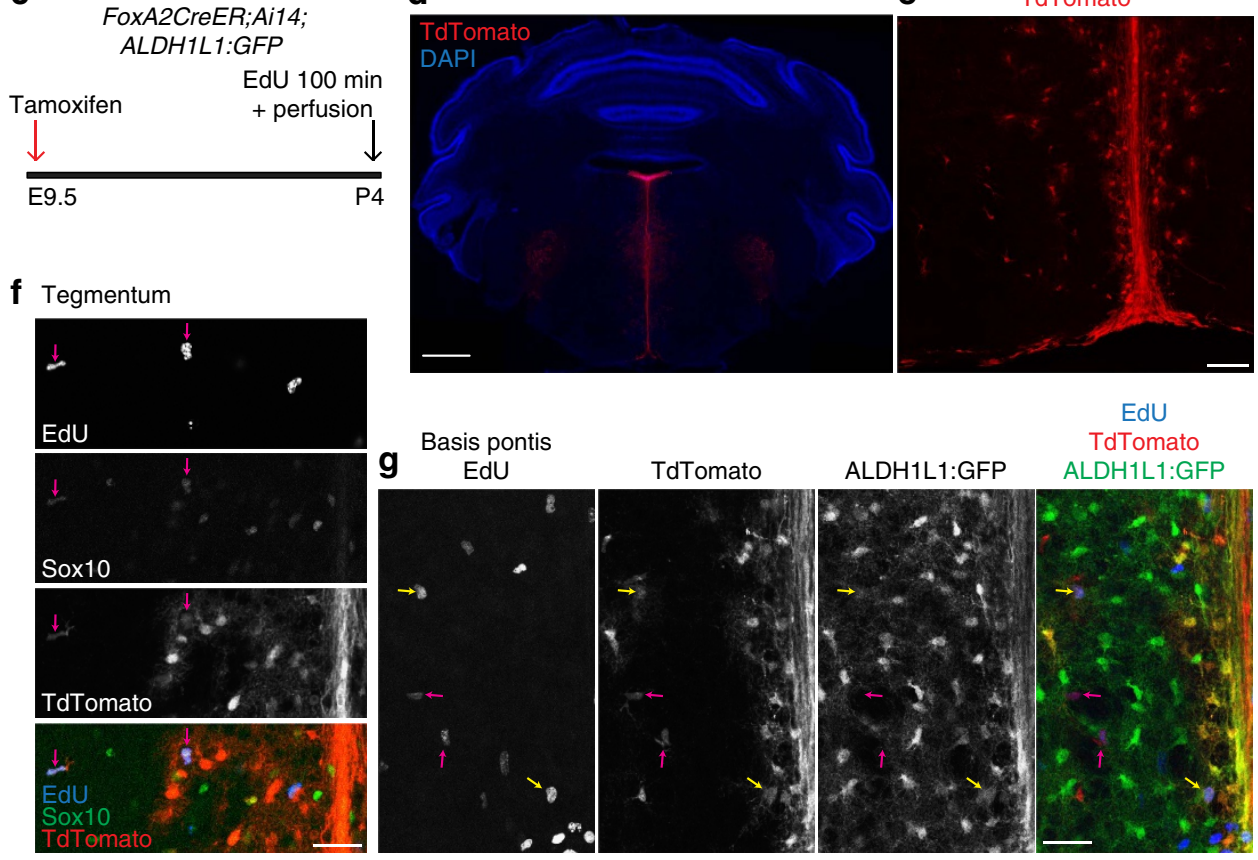

TdTomato ALDH1L1:GFP

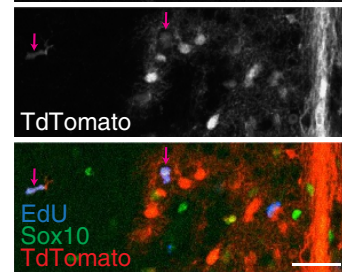

Figure 6 | Proliferative progenitors in postnatal pons deriving from midline domain. (a) Wild-type mouse pons sectioned at oblique angle and stained for vimentin (green) and DAPI (magenta). Note the intense vimentin staining along the midline. Scale bar $=500 \mu$ m. (b) Pons tissue from a mouse perfused 100 min after a single dose of BrdU ( $50 \mathrm{mg} \mathrm{kg}^{-1}$ ) was co-stained for Vimentin, GFAP and BrdU, revealing proliferating cells among fibres of the midline. Scale bar, $20 \mu \mathrm{m}$. (c) Schematic of fate mapping of midline domain. (d) TdTomato labelling by FoxA2CreER;Ai14 in caudal pons, extending from fourth ventricle along midline, and including nearby cells. The midline and nearby cells were clearly labelled, along with other pontine structures known to derive from FoxA2 ${ }^{+}$progenitors (ref. 67): the motor nuclei of cranial nerves V, VI and VII, and raphe nuclei. Scale bar, 500 $\mu$ m. (e) TdTomato expression in fibres along midline and in nearby parenchyma of basis pontis. Scale bar, $100 \mu \mathrm{m}$. (f) Co-labelling of TdTomato, EdU, and Sox10 reveals P4 proliferative oligodendroglia in tegmentum labelled by FoxA2CreER recombination at E9.5. Magenta arrows indicate Sox10 ${ }^{+}$EdU ${ }^{+} \mathrm{TdT}^{+} \mathrm{Cells}_{\mathrm{S}} \mathrm{Scale}$ bar, $50 \mu \mathrm{m}$. (g) Co-labelling of TdTomato, EdU, and ALDH1L1:GFP reveals that some P4 proliferative astrocytes are labelled by FoxA2CreER recombination at E9.5. Yellow arrows indicate ALDH1L1:GFP $+\mathrm{EdU}^{+} \mathrm{TdT}^{+}$cells; magenta arrows indicate GFP-EdU ${ }^{+} \mathrm{TdT}^{+}$cells. Scale bar, $50 \mu \mathrm{m}$. (d-g) In a section of bilateral

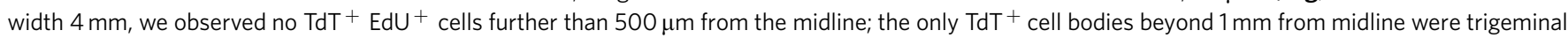
motor neurons. These results show that while the midline domain produces postnatally proliferative astroglia and oligodendroglia, these progeny are regionally restricted.

proliferative astrocytes at all ages from P4 onward (Fig. 7d). In P4 basis pontis, the densities of these cell types were $192.8 \pm 2.7$ proliferative OLPs per $\mathrm{mm}^{2}$ and $73.0 \pm 3.9$ proliferative astrocytes per $\mathrm{mm}^{2}$; in $\mathrm{P} 4$ tegmentum, $151.4 \pm 10.3$ proliferative OLPs per $\mathrm{mm}^{2}$ and $12.4 \pm 2.9$ proliferative astrocytes per $\mathrm{mm}^{2}$. Proliferation persisted to a later age in basis pontis than tegmentum for both cell types: proliferative OLPs in basis pontis showed a sustained peak density from $\mathrm{P} 4$ to $\mathrm{P} 8$, while OLP proliferation in tegmentum peaked at $\mathrm{P} 4$ and began to decline by $\mathrm{P} 8$; proliferative astrocytes plateaued from $\mathrm{P} 0-\mathrm{P} 4$ in basis pontis, but declined in tegmentum as soon as P4. OLP proliferation declined to $<10 \%$ of its peak in both basis pontis and tegmentum by $\mathrm{P} 24$, while astrocyte proliferation decreased to $<10 \%$ of its peak by $\mathrm{P} 8$ in tegmentum, and $\mathrm{P} 12$ in basis pontis. In adults (P64), we observed a small number of proliferative OLPs in both basis pontis $\left(2.41 \pm 0.74\right.$ cells per $\left.\mathrm{mm}^{2}\right)$ and tegmentum $\left(3.15 \pm 1.28\right.$ cells per $\left.\mathrm{mm}^{2}\right)$, comparable to the total proliferation in adult wild-type pons parenchyma (Fig. 3h); no astrocyte proliferation was observed after P12.

The predominance of OLPs at the P4-P8 proliferative peak, and the marked postnatal increase in OL number, raised the question of what proportion of OLPs are actively cycling. We therefore administered BrdU repeatedly to wild-type mice from P4.5-P8, and perfused mice 100 min after the last dose, at P8. We observed BrdU in $86.0 \% \pm 2.6 \%$ of OLPs in basis pontis, and $63.2 \% \pm 4.2 \%$ of OLPs in tegmentum (Supplementary Fig. $4 \mathrm{~g}-\mathrm{i}$ ). This result echoes the denser OLP proliferation in basis pontis than tegmentum (Fig. 7d), suggests that nearly all basis pontis OLPs divided during the postnatal proliferative peak between P4-P8, and may in part account for the greater expansion of the oligodendroglial population in basis pontis compared with tegmentum (Fig. 4f). 
a

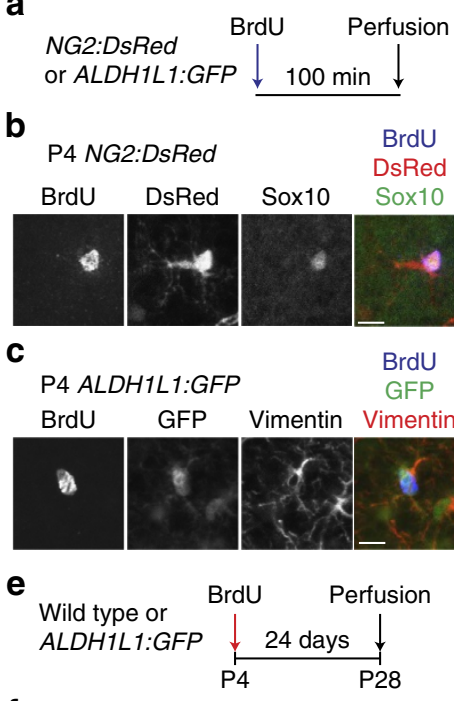

f

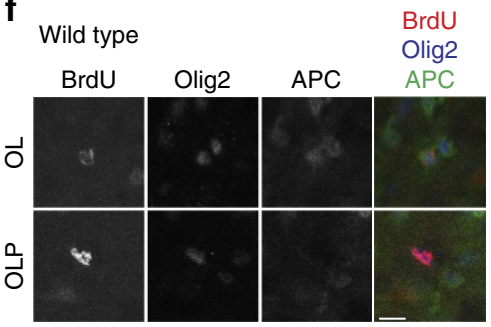

g

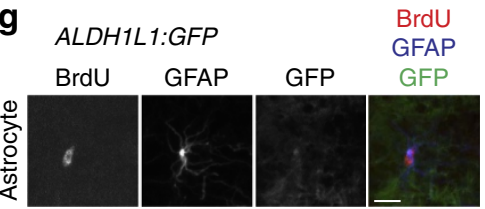

d

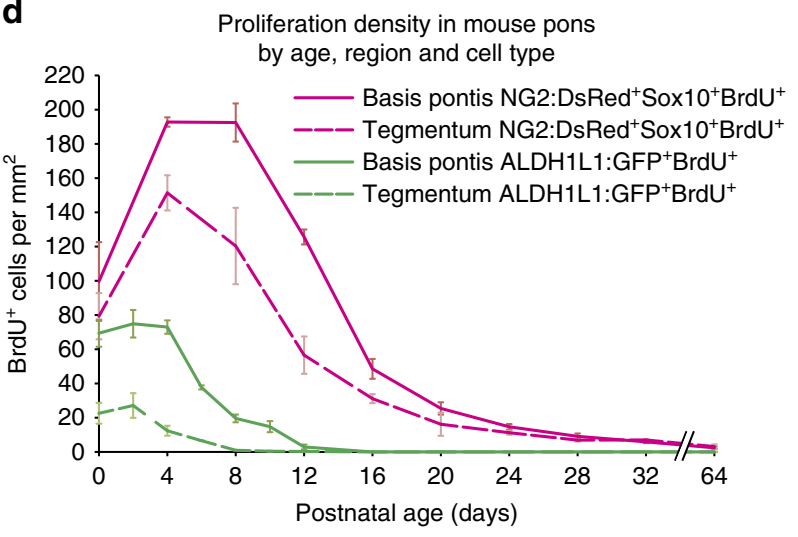

h $\bigcirc$ Astrocytes $\bigcirc$ Oligodendroglia (OL or OLP)

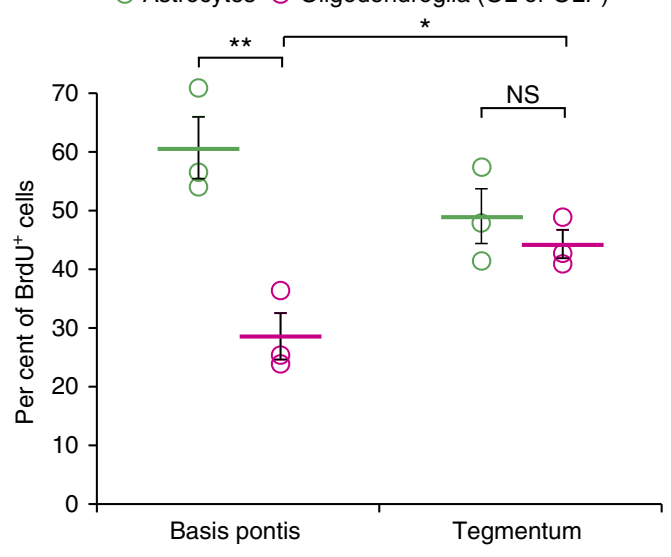

Figure 7 | Glial lineages of parenchymal proliferative progenitors. (a-d) Mice carrying lineage-specific reporter transgenes received a single dose of BrdU (50 mg kg ${ }^{-1}$ ) 100 min before perfusion. (b) Representative proliferative OLP (Sox10 + DsRed ${ }^{+} \mathrm{BrdU}^{+}$) in P4 NG2:DsRed mouse basis pontis. Scale bar, $10 \mu \mathrm{m}$. (c) Representative proliferative parenchymal astrocyte (BrdU ${ }^{+} \mathrm{GFP}^{+}$) in $\mathrm{P} 4$ ALDH1L1:GFP mouse basis pontis, with vimentin ${ }^{+}$processes suggestive of colocalization. Scale bar, $10 \mu \mathrm{m}$. (d) Densities of proliferative OLPs from NG2:DsRed mice (red), and proliferative parenchymal astrocytes from ALDH1L1:GFP mice (green), at ages through childhood and at adulthood; mean \pm s.e.m., $n=3$ mice per strain per timepoint. Three-factor ANOVA confirmed significant differences in proliferation based on cell type $\left(F_{1,56}=491.97, P<0.0001\right)$, region $\left(F_{1,56}=70.18, P<0.0001\right)$, and age $\left(F_{9,56}=97.97, P<0.0001\right)$. (e-h) Wild-type or ALDH1L1:GFP mice were given a single dose of $\mathrm{BrdU}\left(50 \mathrm{mg} \mathrm{kg}^{-1}\right)$ at $\mathrm{P} 4$ and perfused at P28. (f) BrdU ${ }^{+}$cells from basis pontis of mice prepared as in e. Top, representative mature oligodendrocyte (Olig2 ${ }^{+} \mathrm{APC}^{+} \mathrm{BrdU}{ }^{+}$); bottom, representative $\mathrm{OLP}\left(\mathrm{Olig} 2^{+} \mathrm{APC}^{-} \mathrm{BrdU}{ }^{+}\right) . \mathrm{Scale}$ bar, $10 \mu \mathrm{m}$. (g) A representative GFAP ${ }^{+} \mathrm{ALDH1L1}_{\mathrm{GFP}}{ }^{-} \mathrm{BrdU}^{+}$astrocyte from basis pontis of an ALDH1L1:GFP mouse that was given BrdU at P4 and perfused at P28. Scale bar, $10 \mu \mathrm{m}$. (h) Quantitation of BrdU ${ }^{+}$astrocytes and oligodendroglia detected in pons regions after pulse at P4 and chase to P28; graph shows individual replicates with mean \pm s.e.m., $n=3$ mice per strain. Unpaired $t$-test shows BrdU ${ }^{+}$astrocytes outnumber BrdU ${ }^{+}$oligodendroglia in basis pontis $(P=0.0099)$ and are in equal quantity to $\mathrm{BrdU}^{+}$oligodendroglia in tegmentum $(P=0.4320)$, while oligodendroglia are a lower fraction of BrdU ${ }^{+}$cells in P28 basis pontis than tegmentum (See text for interpretations, $P=0.0369$ ). ${ }^{\star} P<0.05 ;{ }^{\star \star} P<0.01 ;$ NS $P>0.05$. NS, not significant.

Despite the finding that proliferative OLPs outnumber proliferative astrocytes, a pulse-chase experiment (Fig. 7e-h) with a single dose of $\mathrm{BrdU}$ at $\mathrm{P} 4$ yielded, among $\mathrm{BrdU}^{+}$cells at P28, more astrocytes $(60.7 \% \pm 5.3 \%)$ than oligodendroglia $(28.6 \% \pm 4.0 \%)$ in basis pontis, and an even ratio of astrocytes to oligodendroglia in tegmentum $(49.1 \% \pm 4.7 \%$ versus $44.3 \% \pm 2.4 \%)$. Taken together with our stereologic counts of oligodendroglia (Fig. 4), this result suggested two possibilities: (1) P4 OLPs may divide so many times by P28 that many of them dilute out their BrdU signal, and/or (2) oligodendroglia might undergo cell death. Consistent with the first possibility, BrdU staining was weaker and more punctate in P28 OLs than in P28 astrocytes (Fig. 7f,g). Further supporting the first possibility, oligodendroglia accounted for a lower per cent of P28 BrdU ${ }^{+}$ cells in basis pontis than in tegmentum (Fig. 7h). Supporting the second possibility, apoptosis has been documented in young $\mathrm{OLs}^{37}$, and in $\mathrm{P} 12$ basis pontis we observed Sox $10^{+}$nuclei surrounded by cytoplasmic, cleaved caspase-3 staining in an OL-like morphology (Supplementary Fig. 8e). We also investigated a third possibility, that P4 'OLPs' might produce astrocytes, by using NG2CreER mice ${ }^{38}$. NG2CreER;Ai14; ALDH1L1:GFP mice receiving tamoxifen at $\mathrm{P} 0$ or $\mathrm{P} 4$ did not show any $\mathrm{TdTomato}^{+}\left(\mathrm{TdT}^{+}\right)$cells expressing ALDH1L1:GFP at $\mathrm{P} 8$, or any $\mathrm{TdT}^{+}$cells expressing GFAP at P60, but instead showed $\mathrm{TdT}^{+}$pericytes and Sox10 ${ }^{+}$or $\mathrm{Olig}{ }^{+} \mathrm{APC}^{+}$cells (Supplementary Fig. 8a-d), consistent with forebrain ${ }^{38}$. Altogether, these experiments show that the postnatal pons has proliferative OLPs and astrocytes, pons OLPs are lineage restricted, and OLPs are the predominant proliferative population at all postnatal ages. 
a

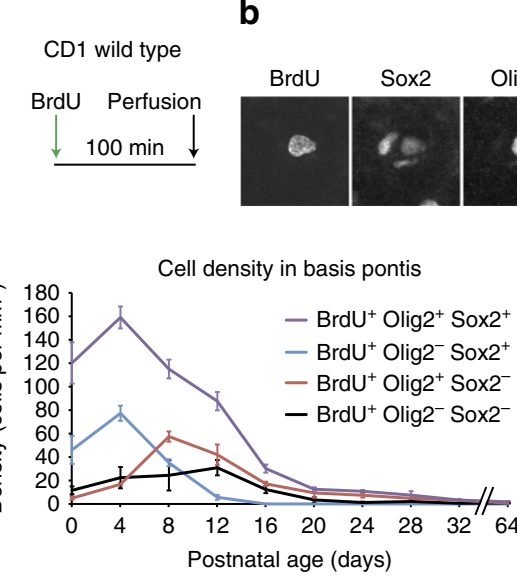

f ALDH1L1:GFP $\stackrel{\text { BrdU }}{\downarrow} 100 \mathrm{~min} \downarrow$

g
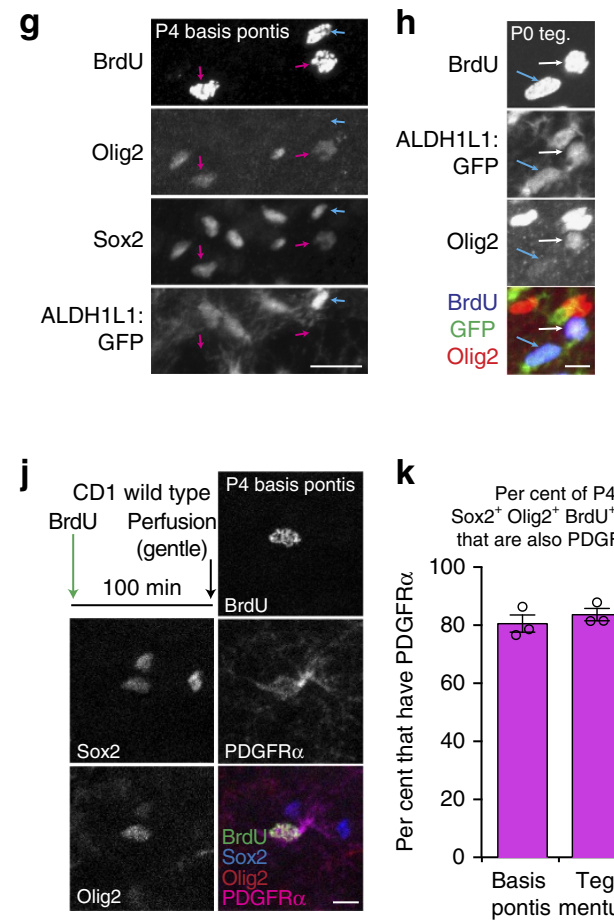

$\mathbf{k}$

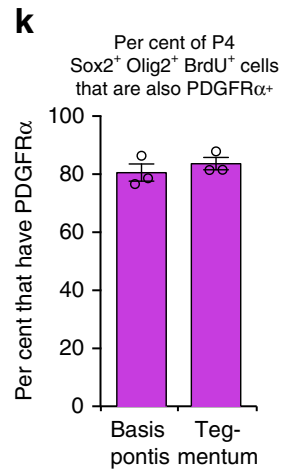

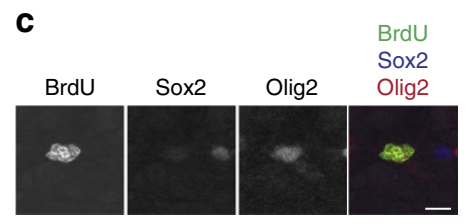

e

e Per cent of $\mathrm{P} 4 \mathrm{Olig2}^{+} \mathrm{BrdU}^{+}$cells that are also Sox $2^{+}$

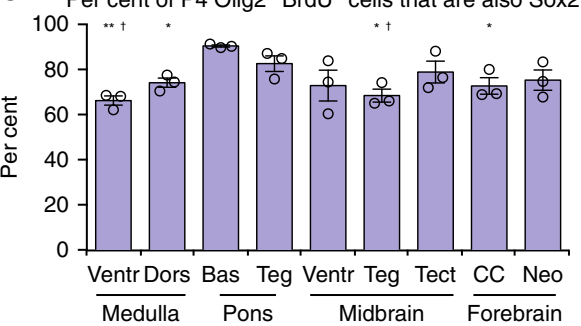

i

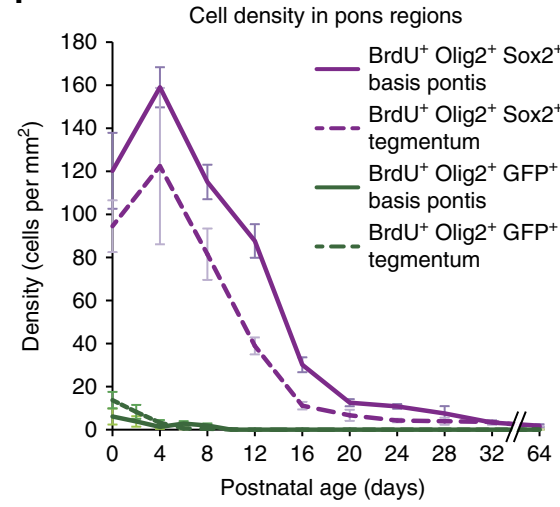

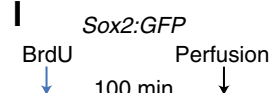

$\downarrow 100 \mathrm{~min} \downarrow$

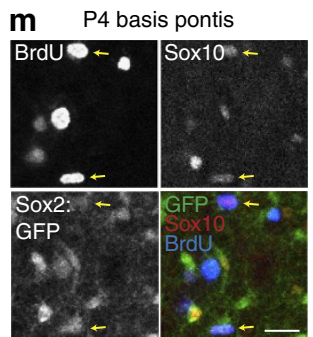

n

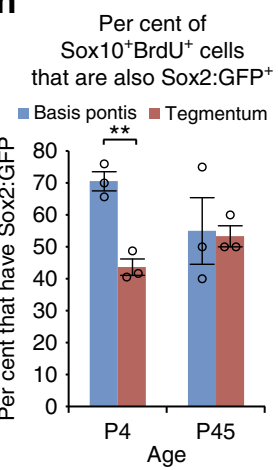

Figure 8 | Sox 2 is expressed in most postnatal pons OLPs. (a-e) CD1 wild-type mice received BrdU 100 min before perfusion. (b) Representative P4 Sox ${ }^{+}$Olig2 ${ }^{+}$BrdU ${ }^{+}$cell. Scale bar, $10 \mu \mathrm{m}$. (c) Representative P16 Sox2 ${ }^{-}$Olig2 ${ }^{+}$BrdU ${ }^{+}$cell. Scale bar, $10 \mu \mathrm{m}$. (d) Breakdown of basis pontis BrdU ${ }^{+}$cell density by Sox2/Olig2 co-staining, through postnatal development; mean \pm s.e.m., $n=3$ mice per timepoint. Sox $2^{+}$Olig2 ${ }^{+}$BrdU ${ }^{+}$cells outnumber any other cell type $\left(F_{1,40} \geq 196.91, P<0.0003\right.$, Bonferroni-adjusted two-way ANOVA based on cell type and age; tegmentum shown in Supplementary Fig. $\left.7 a\right)$. (e) P4 tissue from the indicated regions was analysed for the proportion, among total Olig2 ${ }^{+} \mathrm{BrdU}^{+}$cells, of Sox ${ }^{+} \mathrm{Olig}^{+}{ }^{+} \mathrm{BrdU}{ }^{+}$triple-positive cells; $n=3$ mice, mean \pm s.e.m. Unpaired $t$-test confirmed Olig2 ${ }^{+} \mathrm{BrdU}^{+}$cells were more often Sox $2^{+}$in basis pontis than in ventral medulla $(P=0.0055)$, dorsal medulla $(P=0.0123)$, midbrain tegmentum $(P=0.0152)$ or corpus callosum $(P=0.0380)$, and more often Sox $2^{+}$in pontine tegmentum than ventral medulla $(P=0.0231)$ or midbrain tegmentum $(P=0.0366)$. ${ }^{\star} P<0.05$ versus basis pontis; ${ }^{\star \star} P<0.01$ versus basis pontis; ${ }^{\dagger} P<0.05$ versus pontine tegmentum. (f-h) ALDH1L1:GFP mice received BrdU 100 min before perfusion. (g) Sox2 ${ }^{+}$Olig2 ${ }^{+} \mathrm{BrdU}^{+} \mathrm{ALDH}_{1 \mathrm{~L} 1: G F P}{ }^{-}$cells (pink arrows) and Sox2 ${ }^{+}$ALDH1L1:GFP ${ }^{+} \mathrm{BrdU}^{+}$Olig2 ${ }^{-}$cells (blue arrow) in P4 basis pontis. Scale bar, $20 \mu \mathrm{m}$. (h) BrdU ${ }^{+} \mathrm{ALDH}_{\mathrm{LL1}} \mathrm{GFP}^{+}$Olig2 ${ }^{+}$(white arrow) and $\mathrm{BrdU}^{+} \mathrm{ALDH1L1:GFP}+$ Olig2- (blue arrow) subtypes of proliferative astrocytes in PO tegmentum. Scale bar, $10 \mu \mathrm{m}$. (i) Densities of GFP ${ }^{+} \mathrm{Olig}^{+} \mathrm{BrdU}^{+}$ cells in ALDH1L1:GFP pons, and of Sox $2^{+}$Olig2 ${ }^{+} \mathrm{BrdU}^{+}$cells in wild-type pons; mean \pm s.e.m., $n=3$ mice per strain per timepoint. (j,k) CD1 wild-type mice age $\mathrm{P} 4$ were given $\mathrm{BrdU}$ as in a, perfused with short postfix $\left(100 \mathrm{~min}, 4^{\circ} \mathrm{C}\right)$, cryosectioned, and co-stained as indicated. (j) Representative basis pontis OLP; scale bar, $10 \mu \mathrm{m}$. (k) PDGFR $\alpha$ was expressed in $\sim 80 \%$ of Sox ${ }^{+}$Olig2 ${ }^{+}$BrdU ${ }^{+}$progenitors; $n=3$ mice, mean \pm s.e.m. (I-n) Sox2:GFP mice received BrdU 100 min before perfusion. (m) P4 pons tissue co-stained as indicated. Yellow arrows indicate representative BrdU $+\mathrm{GFP}^{+} \mathrm{Sox} 10^{+}$triple-positive cells. Scale bar, $15 \mu \mathrm{m}$. (n) Sox2:GFP pons regions aged P4 or P45 were analysed for the proportion, among proliferative OLPs (Sox $10^{+} \mathrm{BrdU}^{+}$), of cells expressing Sox2:GFP; this percentage was greater in P4 basis pontis than tegmentum $(P=0.0026$, unpaired $t$-test); $n=3$ mice per timepoint, mean \pm s.e.m.,

${ }^{\star \star} P<0.01$. 
Olig2 and Sox 2 define proliferative progenitor subclasses. To further define the nature of proliferative pontine glial precursors, we used the markers Sox 2 and Olig2, which can be expressed in tumour-propagating glioma cells ${ }^{39,40}$. Using wild-type mice, we delivered a single dose of $\mathrm{BrdU} 100 \mathrm{~min}$ before perfusion (Fig. 8a), and performed co-immunofluorescent labelling of
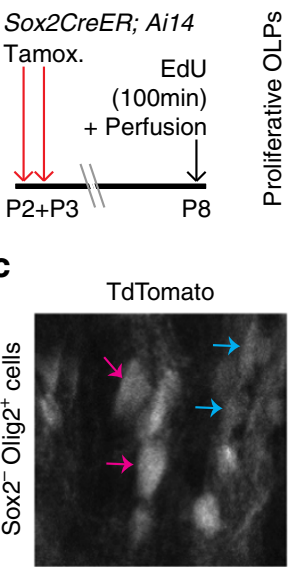

b

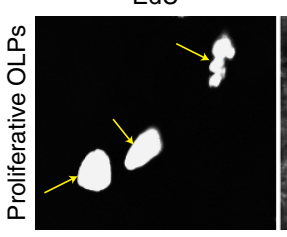

TdTomato

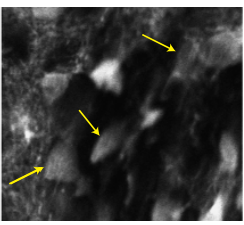

Sox10

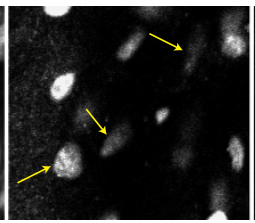

Olig2

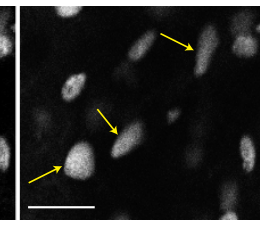

e
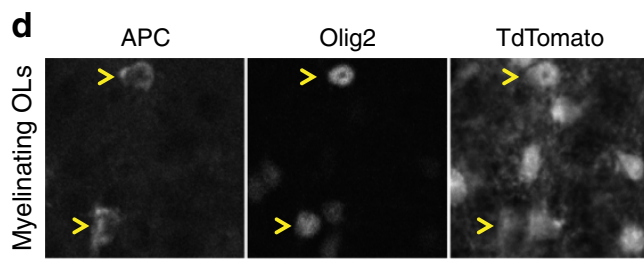

APC Olig2 TdT TdT Sox2 Olig2
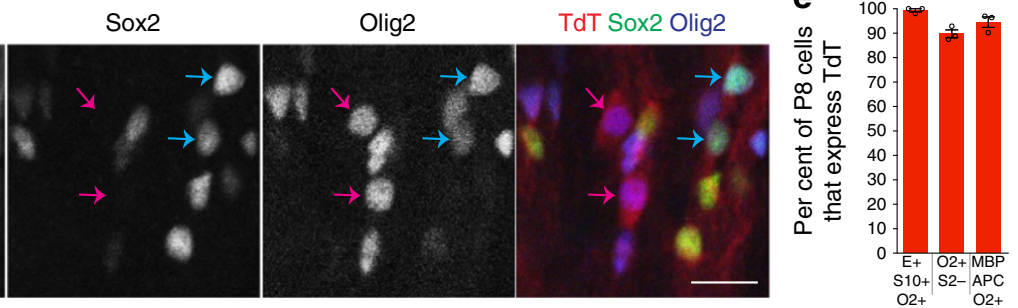

f

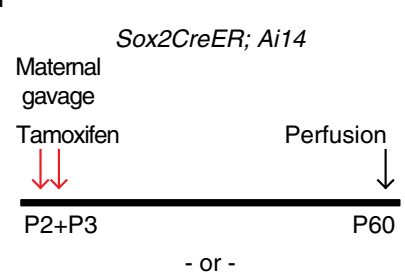

g

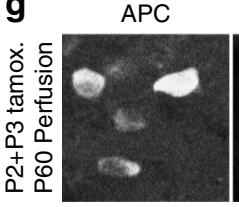

Olig2

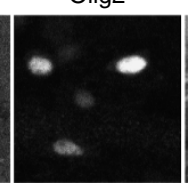

TdTomato APC Olig2 TdT

h

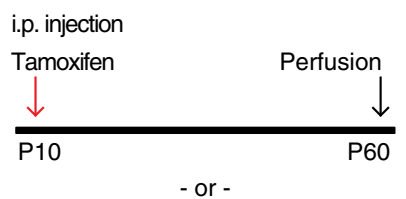

i.p. injection

Tamoxifen
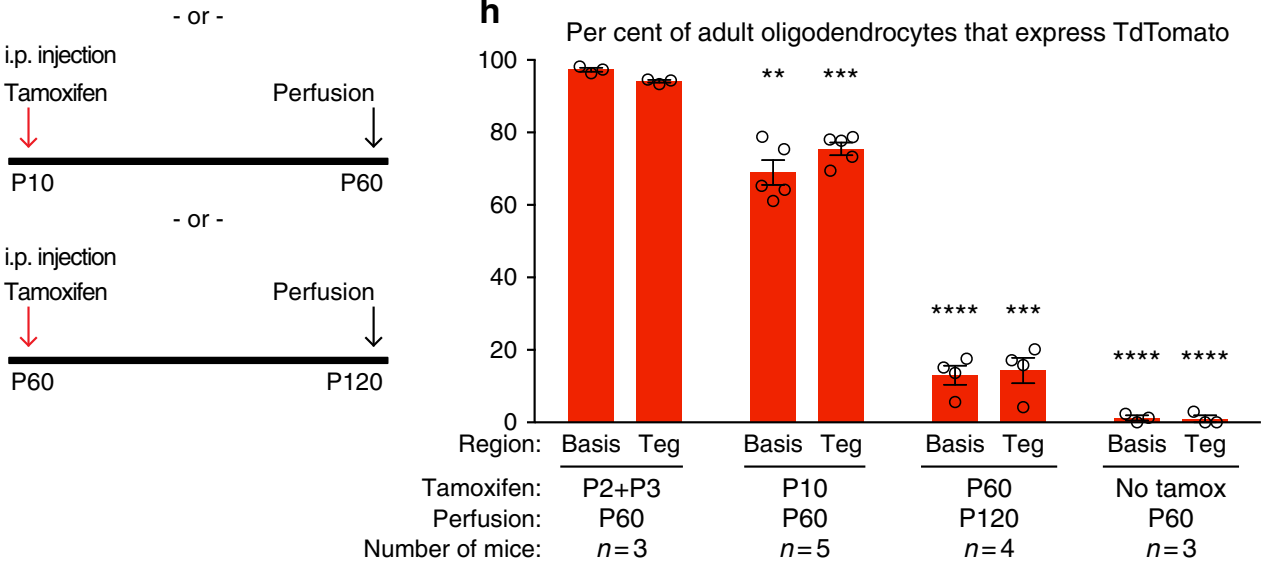

Figure 9 | Postnatal Sox2 ${ }^{+}$progenitors give rise to $\sim 95 \%$ of adult pons OLs. (a-e) Short-term Sox2CreER fate mapping. Sox2CreER;Ai14 pups were given tamoxifen (by maternal gavage) at age P2 and P3, and EdU intraperitoneally at age P8, 100 min before perfusion. (b-d) $\mathrm{TdT}^{+} \mathrm{Olig} 2^{+}$cell types observed in P8 basis pontis; scale bars $=20 \mu \mathrm{m}$. (b) $\mathrm{TdT}^{+} \mathrm{Olig} 2^{+} \mathrm{EdU}{ }^{+}$Sox $10^{+}$proliferative OLPs (arrows). (c) $\mathrm{TdT}^{+}$Olig2 ${ }^{+}$Sox2 ${ }^{+}$(cyan arrows) and $\mathrm{TdT}^{+}$Olig2 ${ }^{+}$Sox2 ${ }^{-}$cells (magenta arrows). (d) $\mathrm{TdT}^{+} \mathrm{Olig} 2^{+} \mathrm{APC}^{+} \mathrm{MBP}^{+}$myelinating $\mathrm{OLs}$ (arrowheads). (e) Quantitation of the proportion of each P8 cell type shown in (b-d) that coexpress TdT, demonstrating origin from postnatal Sox ${ }^{+}$progenitors. Data shown are from basis pontis. ' $E$ ' $=E d U$, 'S10' = Sox10, 'S2' = Sox2, 'O2' = Olig2. Graph shows individual replicates with mean \pm s.e.m. of $n=3$ mice. (f-h) Long-term Sox2CreER;Al14 fate mapping. Tamoxifen induction was performed in one cohort by maternal gavage at P2 and P3, and in a second cohort by IP injection at P10; these two cohorts were perfused at P60. Another cohort received tamoxifen at P60 and was perfused at $\mathrm{P} 120$. (g) $\mathrm{TdT}^{+} \mathrm{Olig} 2^{+} \mathrm{APC}^{+}$mature OLs in adult basis pontis of $\mathrm{P} 2-\mathrm{P} 3$ tamoxifen-induced Sox2CreER;Ai14 mice; scale bar, $20 \mu \mathrm{m}$. (h) Quantitation (by pons region and tamoxifen timing) of the proportion of mature OLs $\left(\mathrm{APC}^{+}\right.$Olig2 ${ }^{+}$) that coexpress TdT, demonstrating origin from Sox $2^{+}$progenitors at the indicated postnatal ages. A cohort of no-tamoxifen control mice showed TdT expression in $\sim 1 \%$ of adult pons OLs. Graph shows individual replicates with mean \pm s.e.m. of the indicated $n$ mice. ${ }^{\star \star} P<0.01$, ${ }^{\star \star \star} P<0.001$, ${ }^{\star * \star \star} P<0.0001$ (unpaired $t$-test, versus the corresponding region of $\mathrm{P} 2-\mathrm{P} 3$ dosed mice). 
BrdU, Olig2 and Sox2 (Fig. 8b-e, Supplementary Figs 7a and 9a,b). The largest pool of $\mathrm{BrdU}^{+}$cells co-expressed Sox2 and Olig2 (Fig. 8b,d; Supplementary Fig. 7a). During the $\mathrm{P} 4$ proliferative peak, the proportion of $\mathrm{BrdU}^{+} \mathrm{Olig}{ }^{+}$cells coexpressing Sox 2 was greater in basis pontis than in ventral or dorsal medulla, midbrain tegmentum, or even corpus callosum; and likewise a greater proportion co-expressed Sox 2 in pontine tegmentum than in midbrain tegmentum (Fig. 8e). Thus the postnatal mouse pons was particularly enriched in Sox $2^{+}$Olig2 ${ }^{+} \mathrm{BrdU}^{+}$progenitors. The remaining progenitors included a Sox ${ }^{+}$Olig2 ${ }^{-} \mathrm{BrdU}^{+}$population peaking at $\mathrm{P} 4$, a Sox $2^{-}$Olig2 ${ }^{+} \mathrm{BrdU}^{+}$population (Fig. 8c,d, Supplementary Fig. 7a) peaking at $\mathrm{P} 8$, and a small Sox $2^{-}$Olig $2^{-} \mathrm{BrdU}^{+}$ population most of which lined blood vessels and had elongated nuclei consistent with endothelial cells. The Sox ${ }^{+}$Olig2 ${ }^{-} \mathrm{BrdU}^{+}$population likely corresponds to proliferative astrocytes, as immunostaining revealed broad Sox2 expression in ALDH1L1:GFP ${ }^{+}$cells (Supplementary Fig. 9c), and as its numbers (Fig. 8d) were comparable to ALDH1L1:GFP ${ }^{+}$BrdU $^{+}$cells (Fig. 7d, Supplementary Fig. 7c).

The Sox $2^{+}$Olig2 ${ }^{+} \mathrm{BrdU}^{+}$cells were predominantly not astrocytes, because in ALDH1L1:GFP mouse pons, Sox ${ }^{+}$Olig2 ${ }^{+}$ $\mathrm{BrdU}^{+}$cells were usually $\mathrm{GFP}^{-}$(Fig. 8f,g; Supplementary Fig. 9b). While a subpopulation of $\mathrm{BrdU}^{+} \mathrm{ALDH1L1:GFP}^{+}$ astrocytes expressed Olig2 (Fig. 8h), such cells were sparse compared with the $\mathrm{BrdU}^{+} \mathrm{Olig} 2{ }^{+} \mathrm{Sox} 2{ }^{+}$progenitors measured in wild-type mouse pons (Fig. 8i, Supplementary Fig. 7c). The total Olig ${ }^{+} \mathrm{BrdU}^{+}$population, measured as the sum of Sox ${ }^{+}$ Olig2 ${ }^{+} \mathrm{BrdU}^{+}$and Sox $2-$ Olig2 ${ }^{+} \mathrm{BrdU}^{+}$populations, showed similar numbers to committed OLPs (Fig. $7 \mathrm{~d}$ ): in basis pontis, a sustained peak from P4 $\left(176 \pm 10\right.$ cells per $\left.\mathrm{mm}^{2}\right)$ to P8 $(173 \pm 4$ cells per $\left.\mathrm{mm}^{2}\right)$; in tegmentum, a peak at P4 (147 \pm 40 cells per $\mathrm{mm}^{2}$ ). And remarkably, at $\mathrm{P} 4$, nearly all $\mathrm{BrdU}^{+} \mathrm{Olig} 2{ }^{+}$cells coexpressed Sox 2 : $90.4 \% \pm 0.4 \%$ in basis pontis and $82.6 \% \pm 3.5 \%$ in tegmentum (Fig. 8e). Altogether, this suggested that the committed OLP population included many Sox $2{ }^{+}$Olig $2{ }^{+}$cells. Sox 2 was long considered a marker of stem cells, but has recently been documented in embryonic OLPs of forebrain and spinal cord $^{41}$. We therefore performed immunostaining in $\mathrm{P} 4$ ALDH1L1:GFP tissue to test whether pontine Sox2 ${ }^{+}$Olig2 ${ }^{+}$ cells co-expressed the canonical OLP marker PDGFR $\alpha$, or the astrocyte reporter ALDH1L1:GFP (PDGFR $\alpha$ and ALDH1L1:GFP were $99 \%$ mutually exclusive in pons, Supplementary Fig. 9f). Remarkably, $89.8 \% \pm 1.7 \%$ of Sox ${ }^{+}$Olig $2^{+}$cells in basis pontis were PDGFR $\alpha^{+}$ALDH1L1:GFP ${ }^{-}$(Supplementary Fig. 9d-f). NG2 protein was similarly localized to Sox2 ${ }^{+}$Olig2 ${ }^{+}$ ALDH1L1:GFP ${ }^{-}$cells (Supplementary Fig. 9g). Next, examining CD1 wild-type mice, we found PDGFR $\alpha$ coexpressed in $80.5 \% \pm 3.0 \%$ of basis pontis Sox $2{ }^{+}$Olig $2{ }^{+} \mathrm{BrdU}^{+}$ cells, and in $83.6 \% \pm 2.1 \%$ of tegmentum Sox $2{ }^{+}$Olig $2{ }^{+} \mathrm{BrdU}^{+}$ cells (Fig. 8j,k). To test Sox 2 coexpression with a third marker of committed oligodendroglia, Sox10, we obtained mice carrying a Sox2:GFP knock-in allele ${ }^{42}$. We performed a single injection of BrdU $100 \mathrm{~min}$ before perfusion at P4 or P45 (Fig. 81), and co-stained pons sections for BrdU, GFP, and the oligo-lineage marker Sox10 (Fig. 8m). We found that $70.5 \% \pm 3.0 \%$ of $\mathrm{Sox} 10^{+} \mathrm{BrdU}^{+}$cells co-expressed Sox2:GFP in the P4 basis pontis, and $43.7 \% \pm 2.6 \%$ in $\mathrm{P} 4$ tegmentum, while Sox $10^{+} \mathrm{BrdU}^{+}$cells in both pons regions showed roughly $50 \%$ Sox2:GFP expression at P45 (Fig. 8n). Altogether, these results indicate that the postnatal pons is rich with Sox $2^{+}$Olig2 ${ }^{+}$ proliferative OLPs, and also contains a smaller, later-peaking, Sox $2^{-}$Olig2 ${ }^{+}$proliferative population.

Postnatal Sox $2^{+}$cells produce over $90 \%$ of adult pons OLs. The presence and timing of Sox $2^{+}$and Sox $2^{-}$subpopulations of proliferative Olig2 ${ }^{+}$cells suggested a possible lineage progression of Sox $2^{+}$Olig2 ${ }^{+}$, to Sox $2^{-}$Olig2 ${ }^{+}$, to myelinating oligodendrocytes. To test whether postnatal Sox ${ }^{+}$cells produced Sox $2^{-}$Olig2 ${ }^{+}$cells and mature OLs, we used Sox2CreER;Ai14 reporter mice. We delivered tamoxifen by maternal gavage at P2-P3, followed by a single dose of EdU 100 min before perfusion at P8 (Fig. 9a). We found that in basis pontis, $\mathrm{TdT}^{+}$cells accounted for: $99.3 \% \pm 0.7 \%$ of Olig2 ${ }^{+}$ Sox $10^{+} \mathrm{EdU}^{+}$proliferative OLPs (Fig. 9b,e); 97.8\% $\pm 2.2 \%$ of Olig2 ${ }^{+}$Sox $2^{+}$cells and $89.7 \% \pm 1.6 \%$ of $\mathrm{Olig} 2^{+}$Sox $2^{-}$ cells (Fig. 9c,e); and $94.5 \% \pm 2.1 \%$ of $\mathrm{APC}^{+} \mathrm{Olig}^{+}{ }^{+} \mathrm{MBP}^{+}$ myelinating OLs (Fig. 9d,e). These results support the hypothesis that postnatal Sox $2^{+}$progenitors generate all stages of the oligodendrocyte lineage. To determine the extent to which postnatal Sox $2^{+}$progenitors contributed oligodendrocytes to the mature pons, we delivered tamoxifen to Sox2CreER;Ai14 mice at P2-P3, P10, or P60 (Fig. 9f), perfused 50-60 days later, and co-stained for TdT, Olig2, and APC. Tamoxifen treatment at $\mathrm{P} 2+\mathrm{P} 3$ led to $\mathrm{TdT}$ expression in $97.3 \% \pm 0.5 \%$ of $\mathrm{APC}^{+} \mathrm{Olig}{ }^{+}$ OLs in P60 basis pontis, and in $94.1 \% \pm 0.4 \%$ of OLs in P60 tegmentum (Fig. 9g,h). Delivery of tamoxifen at P10 labelled $69.0 \% \pm 3.4 \%$ of $\mathrm{P} 60$ basis pontis OLs and $75.5 \% \pm 1.8 \%$ of $\mathrm{P} 60$ tegmentum OLs. Delivery of tamoxifen to P60 mice labelled only $13.0 \% \pm 2.6 \%$ of P120 basis pontis OLs (Fig. 9h) and $14.3 \% \pm 4.3 \%$ of P120 tegmentum OLs. This is consistent with the lower level of proliferative Sox $2^{+}$Olig ${ }^{+}$cells in adult pons (Fig. 8d). A no-tamoxifen control showed TdT expression in only $1.0-1.2 \%$ of P60 pons OLs (Fig. 9h), indicating low spontaneous background recombination.

The Sonic Hedgehog pathway drives embryonic oligodendrogenesis ${ }^{24,43}$; its effector Gli1 has been previously proposed as a postnatal pons progenitor cell marker ${ }^{5}$, and postnatal $\mathrm{Glil}^{+}$forebrain progenitors are known to produce $\mathrm{OLs}^{44}$. We therefore tested if pons OLs were derived from Gli1-expressing progenitors. We found that postnatal tamoxifen treatment at $\mathrm{P} 2-3$ or $\mathrm{P} 10$ in Gli1CreER;Ai14 mice ${ }^{45}$ yielded no $\mathrm{TdT}^{+}$Olig2 ${ }^{+} \mathrm{APC}^{+}$OLs in adult pons, but sparse $\mathrm{TdT}^{+}$ astrocytes positive for $S 100 \beta$ and/or GFAP (Supplementary Fig. 10). Thus Gli1-expressing cells at P2-3 or P10 do not contribute to postnatal pontine oligodendrogenesis, by contrast with Sox $2^{+}$cells. Tamoxifen-treated Sox2CreER;Ai14 mouse pons also contained $\mathrm{TdT}^{+}$astrocytes (Supplementary Fig. 10c), reflecting pontine astrocytes' common Sox2 expression (Supplementary Fig. 9c). In addition to that expected result, our fate mapping experiments demonstrate that postnatal Sox ${ }^{+}$ progenitors populate the adult pons with $\sim 95 \%$ of its oligodendrocytes.

\section{Discussion}

We have shown here that, as in humans ${ }^{3}$, the mouse pons grows markedly after birth, driven by a single wave of proliferation. We identified Sox $2^{+}$Olig2 ${ }^{+}$parenchymal progenitors as the main proliferative progenitor population, and found that postnatal Sox ${ }^{+}$cells give rise to nearly all adult pons OLs.

The postnatal mouse basis pontis quintupled and the tegmentum quadrupled in size, placing the pons among the brain regions with the most pronounced postnatal growthcomparable to that of cortex and hippocampus, but less than that of cerebellum ${ }^{27,28}$. As in humans ${ }^{3}$, the mouse basis pontis experienced more rapid growth and greater proliferation than the tegmentum. There were also interesting differences between human and mouse pons: at birth, the human basis pontis already contains thin myelinated fibres, and proliferation declines after birth; however, the mouse basis pontis experiences its onset of myelination and decline in proliferation during the second 
postnatal week. The $\mathrm{P} 4$ proliferative peak may therefore correspond to a pre-term peak proliferative stage in human pons, which has not yet been studied.

We found that postnatal pontine growth did not involve the addition of new neurons, but rather correlates with a dramatic increase in the oligodendroglial lineage. The basis pontis at P16 contained 18 times as many oligodendroglia as at $\mathrm{P} 0$, and the tegmentum at P16 contained 10 times as many as at P0, suggesting that basis pontis OLPs undergo at least four rounds of postnatal division and tegmentum OLPs undergo at least three. However, the expansion might be carried out by subpopulations dividing five times or more. It is also possible that the population expansion is even greater than observed, but appears reduced due to cell death ${ }^{37}$ or migration out of pons.

We defined three compartments of postnatal progenitor cell proliferation in the pons: VZ, midline and parenchyma. The VZ and midline contributed only a few cells, generally close to these proliferative domains. The parenchymal compartment generated the majority of new cells; some progenitors were proliferative astrocytes, but a greater number corresponded to proliferative OLPs. BrdU ${ }^{+}$Sox $2{ }^{+}$Olig2 ${ }^{+}$OLPs were the largest parenchymal progenitor pool, and postnatal Sox ${ }^{+}$progenitors produced $\sim 95 \%$ of adult pons oligodendrocytes. These observations suggest that Sox $2^{+}$progenitors play a key role in postnatal oligodendrogenesis. A prior study suggested that Sox 2 acts in embryonic spinal cord oligodendroglia to block maturation and myelination during the OL stage ${ }^{41}$; however, we observed that a sizeable subset of postnatal pontine Olig2 ${ }^{+}$cells downregulate Sox 2 while still proliferating, that is, as OLPs. We found a small subpopulation of Sox ${ }^{+}$Olig2 ${ }^{+}$progenitors that continued to proliferate in adult mouse pons. Interestingly, Sox $2{ }^{+} \mathrm{Olig} 2{ }^{+}$cells have also been described in adult human white matter ${ }^{46}$. Our Sox2CreER fate mapping demonstrates that adult Sox ${ }^{+}$cells continue to generate oligodendrocytes in vivo.

The functions of sustained postnatal pontine growth and oligodendrogenesis remain unknown. Oligodendrogenesis is regulated by neuronal activity ${ }^{47,48}$, so the late formation of oligodendrocytes may be linked to postnatal neural activity flowing through the pons. By delaying the onset of myelination, the pons might allow experience to guide which circuits become myelinated. It is appealing to speculate that the maturation of cells in the basis pontis is developmentally coordinated with the maturation of cerebellar target regions, whose growth is mostly postnatal. Interestingly, the middle cerebellar peduncle is among the last tracts in the brain to be myelinated ${ }^{27}$. Given the prominence of motor pathways in the pons, sustained postnatal oligodendrogenesis may allow the development of high-speed circuit conductances in an experience-dependent manner during a critical period of acquisition of motor coordination. Similarly, experience-dependent circuit enhancement could occur in the autonomic regions of the growing postnatal tegmentum that undergo later myelination.

Tumour incidence may be correlated with a tissue's normal developmental proliferative activity ${ }^{49}$. Our findings may partly explain the pons's susceptibility to tumour formation. The pons is the site where Diffuse Intrinsic Pontine Glioma (DIPG), the most lethal paediatric CNS tumour ${ }^{4}$, appears. It is suspected that DIPGs have a progenitor cell origin ${ }^{50}$. This progenitor's identity remains uncertain. OLPs have been shown as a cell of origin for some paediatric forebrain gliomas ${ }^{51,52}$ and adult gliomas ${ }^{53,54}$. DIPGs frequently express Olig2 and Sox2 (ref. 55); our finding of PDGFR $\alpha$ coexpression in the vast majority of $\mathrm{P} 4$ $\mathrm{BrdU}^{+}$Olig $2{ }^{+}$Sox $2{ }^{+}$cells is notable given that PDGFRA is commonly amplified in DIPG ${ }^{55,56}$. Most DIPGs also contain a mutation in Histone $\mathrm{H} 3$ at lysine 27 (refs 57,58), which might epigenetically trap cells in a progenitor state ${ }^{50}$ and prevent repression of Olig2 or Sox2; one study showed that a H3K27M DIPG patient tumour-derived cell line had increased Olig2 expression correlated with decreased $\mathrm{H} 3 \mathrm{~K} 27$ trimethylation at the OLIG2 locus, when compared with mouse forebrain-derived neurospheres ${ }^{59}$. All this suggests that the $\mathrm{BrdU}^{+}$Olig2 ${ }^{+}$Sox ${ }^{+}$ OLPs, which peak at P4 and are enriched in basis pontis, are a prime candidate for DIPG cell of origin. However, despite the ventral preference for growth and proliferation (present study and ref. 3 ) and the propensity of DIPG to spread ventrally ${ }^{60}$, we cannot rule out that some DIPGs might originate dorsally. We observed significant OLP proliferation in the tegmentum at slightly earlier stages than basis pontis; interestingly, a fraction of DIPGs express the dorsal marker Pax3 (ref. 61). We also cannot exclude that DIPG might originate from astrocytes. Astrocytes accounted for $\sim \frac{1}{4}$ of proliferation in $\mathrm{P} 4$ basis pontis; all astrocytes express Sox2, and a subpopulation coexpress Olig2. And finally, it is possible that DIPG may originate prenatally. In one study on embryonic oligodendrogenesis, it was shown that rhombomere 4, within the pons, produces more oligodendroglia than neighbouring segments ${ }^{26}$. In light of our postnatal observations, the embryonic pattern of OLP production ${ }^{26}$ may prepare the pons for its dramatic postnatal growth, and may render the pons rich in potentially gliomagenic progenitors.

The typical presentation of DIPG at 5-9 years led one group to hypothesize a 'second peak' of progenitor cells in 'middle childhood'5. However, when we examined the postnatal pons's normal course of proliferation, we found only a single peak: at birth in human ${ }^{3}$ and at $\mathrm{P} 4$ in mouse (present study). Furthermore, a single proliferative peak was evident for each progenitor cell population. While we cannot exclude that a tumour might arise from the few proliferative cells that persist to later ages, proliferation data favour an origin for DIPG during the single, early-childhood proliferative peak, from Sox ${ }^{+}$Olig2 ${ }^{+}$ progenitors.

This study demonstrates that the postnatal mouse pons undergoes a dramatic increase in size. We have identified proliferative oligodendroglia and astroglia in postnatal pons parenchyma, shown that pons OLPs have early Sox ${ }^{+}$and later Sox $2^{-}$stages, and demonstrated that $\sim 95 \%$ of pons oligodendrocytes derive from postnatal Sox $2^{+}$progenitors. This dramatic pontine cell addition may be linked to the acquisition of key developmental milestones in children, and may predispose the pons to tumour formation. The progenitor cells identified here represent candidates for targeting in future tumour models.

\section{Methods}

Animals. All animal procedures were performed in accordance with $\mathrm{NIH}$ guidelines. Animal protocols were approved and supervised by the UCSF IACUC. Transgenic strains, uses and sources are listed in Supplementary Fig. 1. Transgenic mice were on a mixed background containing CD1 and C57BL/6. 'Wild type' animals in all figures were CD1 (Charles River, Wilmington, MA), except for Fig. 7e-h in which 'wild type' represents GFP-negative littermates of the ALDH1L1:GFP mice used elsewhere in those panels. Mice of both sexes were used The only species used was Mus musculus. BrdU (Sigma-Aldrich, St Louis, MO) was dissolved in sterile phosphate-buffered saline (PBS) and delivered by intraperitoneal injection at a dose of $50 \mathrm{mg} \mathrm{kg}^{-1}$; EdU (Invitrogen, Waltham, MA) was prepared identically and delivered at an equimolar dose, $41 \mathrm{mg} \mathrm{kg}^{-1}$. Tamoxifen was dissolved in sterile-filtered corn oil and delivered by maternal gavage at $5 \mathrm{mg}$ per day, or intraperitoneally into mice P10 or older ( $4 \mathrm{mg}$ per $30 \mathrm{~g}$ body weight). Neonatal intracerebroventricular viral injections were performed in P1 mice using the following stereotaxic coordinates: $(2.0 \mathrm{~mm}$ posterior from intraocular line, $0.8 \mathrm{~mm}$ lateral from midline, $1.5 \mathrm{~mm}$ deep from skin), with a microinjection needle positioned vertically ( 0 degrees). $1 \mu \mathrm{l}$ of virus (Adeno-CMV-Cre, Vector Biolabs, $10^{10}$ p.f.u. $\mathrm{ml}^{-1}$; RCAS-GFP, $\sim 2 \times 10^{7}$ p.f.u. $\mathrm{ml}^{-1}$ ) was delivered into lateral ventricle. Direct injection into the fourth ventricle could have risked accidental puncture of the ventricular surface and labelling of pons parenchyma, as well as inadvertent contact with cerebellar mossy fibre axons from the precerebellar pontine nuclei. Transcardial perfusion was performed as previously described ${ }^{62}$; most samples underwent post-fixation overnight at $4^{\circ} \mathrm{C}$, but for samples used 
in PDGFRalpha and NG2 antibody staining (Fig. 8j,k, Supplementary Fig. 8d-g), post-fixation was limited to $100 \mathrm{~min}$ at $4{ }^{\circ} \mathrm{C}$ so as to preserve antigenicity.

Histology. Because of the placement of the mesencephalic and pontine flexures, a standard coronal section ${ }^{63,64}$ cannot contain the full dorsal-ventral extent of the pons, from basis pontis through tegmentum up to the 4 th ventricle. Therefore, for many experiments (including parts or all of Figs 1,2,4 and 6, and Supplementary Fig. 7) we blocked tissue in an oblique plane, orthogonal to the spinal cord, illustrated in Fig. 1a. This plane contains basis pontis, tegmentum and fourth ventricle, allowing measurement of pons size and comparisons of basis pontis and tegmentum in the same section. For studies of proliferation and/or the ventricular zone, we blocked sections in the standard coronal plane, allowing a wider ventricular space to separate brainstem from cerebellum. For viral fate mapping following lateral ventricle injection (Fig. 5 and Supplementary Fig. 6), sections were coronal or sagittal. For all experiments except PDGFRalpha and NG2 protein staining, tissue sections were prepared at $50 \mu \mathrm{m}$ thickness on a sliding-freezing microtome (Leica Microsystems, Buffalo Grove, IL), following cryoprotection in $30 \%$ sucrose in PBS $+0.1 \%$ sodium azide, and subjected to immunohistochemistry as floating sections. For PDGFRalpha and NG2 protein staining, tissue sections were prepared at $30 \mu \mathrm{m}$ thickness on a Cryostat (Leica), following cryoprotection as above, embedding in O.C.T. (Sakura, Torrance, CA), and frozen storage at $-80^{\circ} \mathrm{C}$; tissue was collected on SuperFrost Plus slides (Fisher Scientific, Hampton, $\mathrm{NH}$ ) and subjected to immunohistochemistry on the slides. Some stains required antigen retrieval in $10 \mathrm{mM}$ citrate buffer $(\mathrm{pH} 6.0)$ at $95^{\circ} \mathrm{C}$ for $10-20 \mathrm{~min}$ or $0.3 \mathrm{M}$ glycine buffer (pH7.4) at $56^{\circ} \mathrm{C}$ for $45 \mathrm{~min}$. All sections were blocked for 30-60 min at room temperature in buffer containing PBS, 0.1\% Triton X-100 (Fisher Scientific), and 2-5\% species-specific serum (depending on host species of secondary antibody); antibodies were diluted in blocking buffer for primary antibody incubation (overnight at $\left.4{ }^{\circ} \mathrm{C}\right)$ and secondary antibody incubation $(2 \mathrm{~h}$ at room temperature); rinses were performed in PBS/0.1\% Triton. Primary antibodies were applied simultaneously, except for anti-BrdU (described below).

Antibodies. Primary antibodies and dilutions are described in Supplementary Fig. 2. Secondary antibodies were from Invitrogen or Jackson Immunoresearch (West Grove, PA), raised in donkey (if one primary antibody in the co-stain was raised in goat) or in goat (in all other cases). IgG subclass-specific secondary antibodies were used where available; secondary antibodies were conjugated to Alexa Fluor 488, 546, 555, 568, 594 or 647 dyes (Invitrogen), or to DyLight 488, Cy3 or Cy5 dye (Jackson Immunoresearch), and all secondary antibodies were used at 1:750 dilution. DAPI (1:5,000; Sigma) was added during secondary antibody incubation; in samples that would subsequently be immunostained for BrdU, DAPI was deferred till the final secondary antibody incubation.

\section{Thymidine analogue detection. For BrdU co-staining, a sequential protocol} was used in which non-BrdU antigens were labelled by primary and secondary antibodies as above; then, fluorophores were fixed into tissue by $15 \mathrm{~min}$ in $4 \% \mathrm{PFA}$, followed by denaturation with $2 \mathrm{~N} \mathrm{HCl}$ at $37^{\circ} \mathrm{C}$ and quenching in boric acid buffer pH8.5 as previously described ${ }^{31}$, and finally, blocking and immunostaining with anti-BrdU primary and fluorophore-conjugated anti-rat secondary antibodies. For EdU detection, the Click-iT EdU Alexa Fluor 647 kit (Invitrogen) was used before immunostaining according to manufacturer's instructions. Control stains were performed to verify that BrdU and EdU methods labelled cells in a distribution comparable to Ki67 immunostaining.

Imaging. Tiled images of entire sections were collected on a Zeiss Axiovert $200 \mathrm{M}$ inverted epifluorescence microscope under $\times 5$ or $\times 10$ objectives (Carl Zeiss, Pleasanton, CA), using the 'Virtual Tissue' module of NeuroLucida/ StereoInvestigator software (MicroBrightField, Williston, VT), an automated stage controller (MicroBrightField), and an AxioCam (Carl Zeiss) or Hamamatsu Orca camera (Hamamatsu, Shizuoka, Japan). High-resolution images were acquired on SP5 Confocal Microscopes (Leica), equipped with LAS AF software, under a $\times 20$ objective and optical zoom to resolutions between $0.757 \mu \mathrm{mpx}^{-1}$ and $0.278 \mu \mathrm{m} \mathrm{px}^{-1}$. Fluorophores were excited by sequential scans using fixedwavelength or white-light lasers, with emission detection windows chosen to avoid bleed-through in single-fluorophore controls. Individual image channels were merged into colour images in batches using CellProfiler software ${ }^{65}$, or for fewimage experiments, manually using Adobe Photoshop (Adobe Systems, San Jose, CA). All images shown are representative of $n \geq 3$ mice.

Size measurements. DAPI-stained mouse pons sections, oriented in the oblique plane described above, were collected as tiled images in NeuroLucida as described, then pons regions were measured offline in NeuroLucida software by drawing contours around basis pontis and whole pons. Basis pontis was defined as 'pons proper $^{36}$, that is, pontine grey nuclei plus adjacent white matter tracts (transverse fasciculus pontis, longitudinal fasciculus pontis, and middle cerebellar peduncle in its ventralmost aspect, that is, excluding portion contacting tegmental nuclei). Pontine tegmentum was defined by subtraction of basis pontis from whole pons. Volumes for basis pontis and tegmentum were computed as the sum of respective regional areas in every second section through pons, times the distance between sections $(100 \mu \mathrm{m}=50 \mu \mathrm{m}$ section thickness $\times$ every second section). For the size study, we used CD1 wild-type mice at ages P0 $(n=3), \mathrm{P} 4(n=4), \mathrm{P} 10(n=3)$, $\mathrm{P} 16(n=3), \mathrm{P} 24(n=3)$ and P64 (adult, $n=3)$.

Tracing of myelinated tracts. The tracing in Fig. 2a, showing major white matter tracts in mouse pons, was obtained by offline NeuroLucida tracing of a MBPstained P16 pons section in the oblique orientation. Tracing was exported as a PostScript file and imported as vector art into Adobe Illustrator (Adobe Systems).

Proliferation maps. Tiled images of mouse brainstem sections, oriented in coronal plane to better distinguish VZ of 4th ventricle, were co-stained for BrdU, Vimentin, and GFAP, then imaged in StereoInvestigator software and traced offline. Markers were placed at the location of every $\mathrm{BrdU}^{+}$nucleus, with distinct markers for cells in VZ, cells contacting Vimentin ${ }^{+}$processes along the midline, cells contacting $\mathrm{GFAP}^{+}$processes branching off the midline, and cells in parenchyma. Maps were exported as postscript files and imported as vector art into Adobe Illustrator.

Proliferation measurements. Mouse brainstem sections were immunostained for BrdU and other markers as described above. For VZ proliferation (Fig. 3f), we used StereoInvestigator to perform live counting under a $\times 10$ objective, identifying $\mathrm{BrdU}^{+}$cells in VZ by their overlap with the dense DAPI zone along the fourth ventricle; ventricular surface length was also measured live in StereoInvestigator. We analysed every third section (in ages P0-P12) or every sixth section (in ages P16 and up) through the pontine VZ. Density was computed as the ratio of $\mathrm{BrdU}^{+}$ VZ cells to VZ length. For measurements of proliferation density among parenchymal populations (Figs 3,7 and 8; Supplementary Figs 3 and 7), counting was done using confocal images acquired as overlapping individual fields at $0.505 \mu \mathrm{m} \mathrm{px}^{-1}$ resolution spanning the entire (lateral-medial-lateral) extent of basis pontis or pontine tegmentum; we used StereoInvestigator for manual alignment of individual fields, region-area measurements and counting of $\mathrm{BrdU}^{+}$cells and colocalized markers (Sox2, Olig2, GFP, Sox10 and DsRed). For pons parenchyma, proliferative cell density was computed as the ratio of $\mathrm{BrdU}^{+}$cells to area of basis or pontine tegmentum. For the pontine midline domain, which was defined as the medial white matter space in the section and at all ages was within $50 \mu \mathrm{m}$ of the midline, proliferative cell density was defined as the ratio of $\mathrm{BrdU}^{+}$ cells to length of midline. For midbrain, medulla and forebrain regions, proliferation density was measured using a single confocal field per animal, taken at the following sites: superior colliculus (midbrain tectum), dorsal raphe nucleus (midbrain tegmentum), interpeduncular nucleus (ventral midbrain), prepositus hypoglossal nucleus (dorsal medulla), inferior olivary nucleus (ventral medulla) and dorsal to the anterior horn of the lateral ventricle (corpus callosum and neocortex, both imaged in the same section). We used $n=3$ animals per timepoint, and up to 10 timepoints per strain: wild-type and NG2:DsRed mice were aged at 4-day intervals from P0-P32, plus P64 (adult); ALDH1L1:GFP mice were aged at 2-day intervals from P0-P12, plus P16, P20 and P64 (adult). For quantitation of proliferative OLPs in Sox2CreER fatemap (Fig. 9e), counts of P8 EdU ${ }^{+}$Olig $2^{+}$ Sox $10^{+}$cells were performed similarly in basis pontis, and the percentage of those cells coexpressing TdTomato (TdT) was reported.

BrdU fatemap counts. BrdU labelled cells in the pulse-chase experiment (Fig. 7e-h) were imaged and counted offline in basis pontis and tegmentum as in acute proliferation experiments (described above). Astrocyte counts were from ALDH1L1:GFP mice and included cells that were ALDH1L1:GFP ${ }^{+} \mathrm{BrdU}^{+}$and/or $\mathrm{GFAP}^{+} \mathrm{BrdU}^{+}$. Oligodendroglia counts were from wild-type $\left(\mathrm{GFP}^{-}\right)$littermates of the $\mathrm{GFP}^{+}$mice and included cells that were $\mathrm{Olig}^{+} \mathrm{BrdU}^{+}$and/or $\mathrm{APC}^{+}$ $\mathrm{BrdU}^{+} . n=3$ mice were used per strain.

Percentage counts and non-proliferative cell density counts. For measurements of the Sox2:GFP ${ }^{+}$subpopulation of Sox $10^{+} \mathrm{BrdU}^{+}$cells at P45 (in Fig. 8l), overlapping confocal fields spanning the basis pontis or pontine tegmentum were acquired from one section per animal at resolution of $0.505 \mu \mathrm{mpx}^{-1}$; image alignment and exhaustive counting were performed offline in StereoInvestigator. For P4, the same procedure was performed, except due to the abundant proliferation, cells were selected by systematic uniform random sampling using the Area Fractionator probe and an area sampling fraction of 1/16. $n=3$ animals were used per timepoint. The fidelity of the Sox2:GFP reporter, previously demonstrated in ref. 42, was confirmed in pons by control co-immunostain of GFP and Sox2 protein. Density counts for the PDGFR $\alpha /$ ALDH1L1:GFP/Sox2/Olig2 costain (Supplementary Fig. 9f) were performed using the same sampling fraction and $n$, and a single confocal field for each region. For quantitation of PDGFR $\alpha$ coexpression among Sox ${ }^{+} \mathrm{Olig} 2{ }^{+} \mathrm{BrdU}{ }^{+}$cells (Fig. 8k), exhaustive counts were performed from a single confocal field per animal in each of basis pontis (encompassing midline, transverse fasciculus pontis, pontine nuclei and corticospinal tract), tegmentum (adjacent to fourth ventricle) and neocortex (dorsal to anterior horn of lateral ventricle). For counts of non-proliferative cells in shortterm Sox2CreER;Ai14 fate mapping (Fig. 9e), systematic uniform random sampling within basis pontis was similarly performed offline, using confocal images from 
$n=3$ animals and an area sampling fraction of 1/16; average numbers of cells assessed for TdT positivity per animal were 90 myelinating OLs (range 65 to 123) and 83 cells positive for Olig2 and/or Sox2 (range 67-104). For measurements of the $\mathrm{TdT}^{+}$percentage of $\mathrm{APC}^{+}$Olig2 ${ }^{+}$oligodendrocytes in adult Sox2CreER;Ai14 mice (Fig. 9g), systematic uniform random sampling through basis pontis or tegmentum was performed live under a $\times 20$ objective using the Optical Fractionator probe; the number of OLs counted per region per animal averaged 193, with minimum of 106 and maximum of 382. $n \geq 3$ animals were used per cohort, with specific $n$ indicated in the figure.

Stereologic counts. For counts of oligodendroglia, we performed co-immunofluorescent labelling of Olig2, Sox10, and APC, followed by live systematic uniform random sampling under a $20 \mathrm{x}$ objective using the Optical Fractionator probe in StereoInvestigator. OLs expressed APC plus at least one of Olig2 and Sox10; OLPs expressed both Olig2 and Sox10 but not APC. Thus a cell was only considered oligodendroglial if it expressed at least two of the three markers. For all samples the counting frame was $50 \times 50 \mu \mathrm{m}$, and cell nuclei were used to define cell location with respect to the optical disector. Average mounted section thickness varied with age from 30 to $50 \mu \mathrm{m}$. Because of pons growth over postnatal development, and also because of the $5 \mathrm{x}$ size difference between mouse tegmentum and basis pontis, we chose the sampling parameters on a per-region, per-animal basis, to count an average of at least 200 cells per region per animal. Grid step size varied from $200 \times 200 \mu \mathrm{m}$ (at P0) to $350 \times 350 \mu \mathrm{m}$ (at P64) in basis pontis, and from $480 \mu \mathrm{m}$ (at P0) to $800 \mu \mathrm{m}$ (at P64) in pontine tegmentum; section interval varied from 4 (at $\mathrm{P} 0$ ) to 12 (at P64). The resulting number of oligodendroglia counted per basis pontis averaged 204, with a minimum of 83 and maximum of 305 ; the number of oligodendroglia counted per tegmentum averaged 242 , with a minimum of 127 and maximum of 378. Stereologic counts of OLs and OLPs in basis pontis and tegmentum were obtained from three separate animals per timepoint, and mean counts and standard errors were computed from those three replicates.

Statistics. Means, standard errors, and $P$-values (by two-tailed unpaired $t$-test) were computed in Microsoft Excel (Microsoft, Redmond, WA). Data were graphed in Excel or GraphPad Prism (GraphPad, La Jolla, CA). Three-way and two-way analysis of variance (ANOVA) was performed in Stata 13 (StataCorp, College Station, TX). Bonferroni correction was performed for multiple pairwise ANOVA comparisons of proliferation among regions (Fig. 3, Supplementary Fig. 3) and cell types (Fig. 8, Supplementary Fig. 6). For the three-way ANOVA in Fig. 7d, comparing proliferative cell density across ages, regions, and cell types $\left(\mathrm{ALDH1L1}: \mathrm{GFP}^{+} \mathrm{BrdU}^{+}\right.$astrocytes versus Sox10 $\left.{ }^{+} \mathrm{NG} 2: \mathrm{DsRed}^{+} \mathrm{BrdU}^{+} \mathrm{OLPs}\right)$, comparison was limited to the 7 timepoints measured in both strains (P0, P4, P8, $\mathrm{P} 12, \mathrm{P} 16, \mathrm{P} 20, \mathrm{P} 64)$; the three additional timepoints uniquely measured in each strain (P2, P6, and P10 in ALDH1L1:GFP; P24, P28, and P32 in NG2:DsRed) were omitted from that calculation. A separate ANOVA was performed pooling single-strain timepoints with both-strain timepoints, in six groups: $\mathrm{P} 0-\mathrm{P} 2, \mathrm{P} 4$, P6-P10, P12, P16, P20-P32, and P64; $P$-values from this second ANOVA were as small as or smaller than those produced by the first. Therefore we reported the first, more conservative result. For all experiments, a minimum $n$ of three mice per timepoint was chosen based not on power analysis but on past studies of brain region growth ${ }^{28}$ and hindbrain development ${ }^{26}$. The obvious differences in tissue size throughout postnatal development mooted attempts at blinding to sample identity. Distributions were assumed to be normal but this was not formally tested. No data points were excluded from analysis.

Data availability. The data that support the findings of this study are available from the corresponding author on request.

\section{References}

1. Johnson, M. H. Functional brain development in humans. Nat. Rev. Neurosci. 2, 475-483 (2001)

2. Stecca, B. \& Ruiz i Altaba, A. Brain as a paradigm of organ growth: Hedgehog-Gli signaling in neural stem cells and brain tumors. J. Neurobiol. 64, 476-490 (2005).

3. Tate, M. C. et al. Postnatal growth of the human pons: A morphometric and immunohistochemical analysis. J. Comp. Neurol. 523, 449-462 (2015).

4. Hargrave, D., Bartels, U. \& Bouffet, E. Diffuse brainstem glioma in children: critical review of clinical trials. Lancet Oncol. 7, 241-248 (2006).

5. Monje, M. et al. Hedgehog-responsive candidate cell of origin for diffuse intrinsic pontine glioma. Proc. Natl Acad. Sci. USA 108, 4453-4458 (2011).

6. España, R. A. \& Scammell, T. E. Sleep neurobiology from a clinical perspective. Sleep 34, 845-858 (2011).

7. Song, G., Yu, Y. \& Poon, C. S. Cytoarchitecture of pneumotaxic integration of respiratory and nonrespiratory information in the rat. J. Neurosci. 26, 300-310 (2006).

8. Kawamura, H., Gunn, C. G. \& Frohlich, E. D. Cardiovascular alteration by nucleus locus coeruleus in spontaneously hypertensive rat. Brain Res. 140, 137-147 (1978)
9. Brodal, A. The Cranial Nerves; Anatomy And Anatomicoclinical Correlations (Blackwell Scientific Publications, 1965).

10. Brodal, P. \& Bjaalie, J. G. Organization of the pontine nuclei. Neurosci. Res. 13, 83-118 (1992).

11. Matano, S., Stephan, H. \& Baron, G. Volume comparisons in the cerebellar complex of primates. I. Ventral pons. Folia Primatol. (Basel) 44, 171-181 (1985).

12. Altman, J. \& Bayer, S. A. Prenatal development of the cerebellar system in the rat. II. Cytogenesis and histogenesis of the inferior olive, pontine gray, and the precerebellar reticular nuclei. J. Comp. Neurol. 179, 49-75 (1978).

13. Altman, J. \& Bayer, S. A. Development of the brain stem in the rat. II. Thymidine-radiographic study of the time of origin of neurons of the upper medulla, excluding the vestibular and auditory nuclei. J. Comp. Neurol. 194, 37-56 (1980).

14. Altman, J. \& Bayer, S. A. Development of the brain stem in the rat. IV. Thymidine-radiographic study of the time of origin of neurons in the pontine region. J. Comp. Neurol. 194, 905-929 (1980).

15. Altman, J. \& Bayer, S. A. Development of the precerebellar nuclei in the rat: IV. The anterior precerebellar extramural migratory stream and the nucleus reticularis tegmenti pontis and the basal pontine gray. J. Comp. Neurol. 257, 529-552 (1987).

16. Altman, J. \& Bayer, S. A. Development of the precerebellar nuclei in the rat: III. The posterior precerebellar extramural migratory stream and the lateral reticular and external cuneate nuclei. J. Comp. Neurol. 257, 513-528 (1987).

17. Altman, J. \& Bayer, S. A. Development of the precerebellar nuclei in the rat: I. The precerebellar neuroepithelium of the rhombencephalon. J. Comp. Neurol. 257, 477-489 (1987)

18. Kiecker, C. \& Lumsden, A. Compartments and their boundaries in vertebrate brain development. Nat. Rev. Neurosci. 6, 553-564 (2005).

19. Oury, F. et al. Hoxa2- and rhombomere-dependent development of the mouse facial somatosensory map. Science 313, 1408-1413 (2006).

20. Moreno-Bravo, J. A. et al. Role of Shh in the development of molecularly characterized tegmental nuclei in mouse rhombomere 1. Brain Struct. Funct. 219, 777-792 (2013).

21. Ray, R. S. \& Dymecki, S. M. Rautenlippe Redux -- toward a unified view of the precerebellar rhombic lip. Curr. Opin. Cell Biol. 21, 741-747 (2009).

22. Das, G. D. Gliogenesis and ependymogenesis during embryonic development of the rat. An autoradiographic study. J. Neurol. Sci. 43, 193-204 (1979).

23. Ono, K. et al. Early development of the oligodendrocyte in the embryonic chick metencephalon. J. Neurosci. Res. 48, 212-225 (1997).

24. Davies, J. E. \& Miller, R. H. Local sonic hedgehog signaling regulates oligodendrocyte precursor appearance in multiple ventricular zone domains in the chick metencephalon. Dev. Biol. 233, 513-525 (2001).

25. Vallstedt, A., Klos, J. M. \& Ericson, J. Multiple dorsoventral origins of oligodendrocyte generation in the spinal cord and hindbrain. Neuron 45, 55-67 (2005).

26. Miguez, A. et al. Opposing roles for Hoxa2 and Hoxb2 in hindbrain oligodendrocyte patterning. J. Neurosci. 32, 17172-17185 (2012).

27. Chuang, N. et al. An MRI-based atlas and database of the developing mouse brain. Neuroimage 54, 80-89 (2011).

28. Fink, G. R., Zilles, K. \& Schleicher, A. Postnatal development of forebrain regions in the autoimmune NZB-mouse. A model for degeneration in neuronal systems. Anat. Embryol. (Berl) 183, 579-588 (1991).

29. Gibson, P. et al. Subtypes of medulloblastoma have distinct developmental origins. Nature 468, 1095-1099 (2010).

30. Hua, H. \& Kearsay, S. E. Monitoring DNA replication in fission yeast by incorporation of 5-ethynyl-2'-deoxyuridine. Nucleic Acids Res. 39, e60 (2011).

31. Ponti, G. et al. Cell cycle and lineage progression of neural progenitors in the ventricular-subventricular zones of adult mice. Proc. Natl Acad. Sci. USA 110 E1045-E1054 (2013).

32. Cahoy, J. D. et al. A transcriptome database for astrocytes, neurons, and oligodendrocytes: a new resource for understanding brain development and function. J. Neurosci. 28, 264-278 (2008).

33. Madisen, L. et al. A robust and high-throughput Cre reporting and characterization system for the whole mouse brain. Nat. Neurosci. 13, 133-140 (2010).

34. Holland, E. C., Hively, W. P., DePinho, R. A. \& Varmus, H. E. A constitutively active epidermal growth factor receptor cooperates with disruption of G1 cell-cycle arrest pathways to induce glioma-like lesions in mice. Genes Dev. 12, 3675-3685 (1998).

35. Park, E. J. et al. System for tamoxifen-inducible expression of cre-recombinase from the Foxa2 locus in mice. Dev. Dyn. 237, 447-453 (2008).

36. Ziskin, J. L., Nishiyama, A., Rubio, M., Fukaya, M. \& Bergles, D. E. Vesicular release of glutamate from unmyelinated axons in white matter. Nat. Neurosci. 10, 321-330 (2007).

37. Barres, B. A. et al. Cell death and control of cell survival in the oligodendrocyte lineage. Cell 70, 31-46 (1992). 
38. Zhu, X. et al. Age-dependent fate and lineage restriction of single NG2 cells. Development 138, 745-753 (2011).

39. Ligon, K. L. et al. Olig2-regulated lineage-restricted pathway controls replication competence in neural stem cells and malignant glioma. Neuron 53, 503-517 (2007).

40. Suvà, M. L. et al. Reconstructing and reprogramming the tumor-propagating potential of glioblastoma stem-like cells. Cell 157, 580-594 (2014).

41. Hoffmann, S. A. et al. Stem cell factor Sox 2 and its close relative Sox 3 have differentiation functions in oligodendrocytes. Development 141, 39-50 (2014).

42. Arnold, K. et al. Sox $2\left(^{+}\right)$adult stem and progenitor cells are important for tissue regeneration and survival of mice. Cell Stem Cell 9, 317-329 (2011).

43. Tekki-Kessaris, N. et al. Hedgehog-dependent oligodendrocyte lineage specification in the telencephalon. Development 128, 2545-2554 (2001).

44. Tong, C. K. et al. A dorsal SHH-dependent domain in the V-SVZ produces large numbers of oligodendroglial lineage cells in the postnatal brain. Stem Cell Rep. 5, 461-470 (2015).

45. Ahn, S. \& Joyner, A. L. Dynamic changes in the response of cells to positive hedgehog signaling during mouse limb patterning. Cell 118, 505-516 (2004).

46. Oliver-De La Cruz, J. et al. SOX2 ${ }^{+}$cell population from normal human brain white matter is able to generate mature oligodendrocytes. PLOS ONE 9, e99253 (2014).

47. Barres, B. A. \& Raff, M. C. Proliferation of oligodendrocyte precursor cells depends on electrical activity in axons. Nature 361, 258-260 (1993).

48. Gibson, E. M. et al. Neuronal activity promotes oligodendrogenesis and adaptive myelination in the mammalian brain. Science 344, 1252304 (2014).

49. Tomasetti, C. \& Vogelstein, B. Cancer etiology. Variation in cancer risk among tissues can be explained by the number of stem cell divisions. Science 347, 78-81 (2015).

50. Gajjar, A., Pfister, S. M., Taylor, M. D. \& Gilbertson, R. J. Molecular insights into pediatric brain tumors have the potential to transform therapy. Clin. Cancer Res. 20, 5630-5640 (2014).

51. Liu, C. et al. Mosaic analysis with double markers reveals tumor cell of origin in glioma. Cell 146, 209-221 (2011).

52. Lindberg, N. et al. Oncogenic signaling is dominant to cell of origin and dictates astrocytic or oligodendroglial tumor development from oligodendrocyte precursor cells. J. Neurosci. 34, 14644-14651 (2014).

53. Persson, A. I. et al. Non-stem cell origin for oligodendroglioma. Cancer Cell 18, 669-682 (2010)

54. Galvao, R. P. et al. Transformation of quiescent adult oligodendrocyte precursor cells into malignant glioma through a multistep reactivation process. Proc. Natl Acad. Sci. USA 111, E4214-E4223 (2014).

55. Puget, S. et al. Mesenchymal transition and PDGFRA amplification/mutation are key distinct oncogenic events in pediatric diffuse intrinsic pontine gliomas. PLoS ONE 7, e30313 (2012).

56. Zarghooni, M. et al. Whole-genome profiling of pediatric diffuse intrinsic pontine gliomas highlights platelet-derived growth factor receptor $\alpha$ and poly (ADP-ribose) polymerase as potential therapeutic targets. J. Clin. Oncol. 28, 1337-1344 (2010)

57. Schwartzentruber, J. et al. Driver mutations in histone H3.3 and chromatin remodelling genes in paediatric glioblastoma. Nature 482, 226-231 (2012).

58. Wu, G. et al. Somatic histone $\mathrm{H} 3$ alterations in pediatric diffuse intrinsic pontine gliomas and non-brainstem glioblastomas. Nat. Genet. 44, 251-253 (2012)

59. Chan, K. M. et al. The histone H3.3K27M mutation in pediatric glioma reprograms H3K27 methylation and gene expression. Genes Dev. 27, 985-990 (2013).

60. Fischbein, N. J. et al. Radiologic classification of brain stem tumors: correlation of magnetic resonance imaging appearance with clinical outcome. Pediatr. Neurosurg. 24, 9-23 (1996).

61. Misuraca, K. L. et al. Pax3 expression enhances PDGF-B-induced brainstem gliomagenesis and characterizes a subset of brainstem glioma. Acta Neuropathol. Commun. 2, 134 (2014).
62. Han, Y. G. et al. Hedgehog signaling and primary cilia are required for the formation of adult neural stem cells. Nat. Neurosci. 11, 277-284 (2008).

63. Franklin, K. B. J. \& Paxinos, G. The Mouse Brain in Stereotaxic Coordinates (Academic Press, 1997).

64. Paxinos, G. Atlas of the Developing Mouse Brain at E17.5, P0 and P6 (Elsevier, 2007).

65. Carpenter, A. E. et al. CellProfiler: image analysis software for identifying and quantifying cell phenotypes. Genome Biol. 7, R100 (2006).

66. Alonso, A. et al. Development of the serotonergic cells in murine raphe nuclei and their relations with rhombomeric domains. Brain Struct. Funct. 218, 1229-1277 (2013).

67. Norton, W. H. et al. Monorail/Foxa2 regulates floorplate differentiation and specification of oligodendrocytes, serotonergic raphe neurones and cranial motoneurones. Development 132, 645-658 (2005).

\section{Acknowledgements}

We thank the following investigators for providing transgenic strains used in this study: Lily Jan, UCSF (NG2DsRed); Alexandra Joyner, Memorial Sloan-Kettering Cancer Center (Gli1CreER); Ross Metzger, UCSF (FoxA2CreER). We thank the following investigators for providing antibodies: C. Stiles, Dana Farber Cancer Institute (anti-Olig2 monoclonal and polyclonal); W. Stallcup, Sanford-Burnham-Prebys Medical Discovery Institute (anti-PDGFRalpha polyclonal). We thank the UCSF Library for use of Stata 13 software, Ricardo Romero-Rodriguez for excellent technical support with histology, Saul Villeda for use of a freezing stage, Patrick McQuillen and William Walantus for support with microscopy, Tarja Yvanka de Soysa for pilot stereotaxic injections, and members of the Alvarez-Buylla and Rowitch laboratories for advice on experiments and this manuscript. This work was supported by grants from the Pediatric Brain Tumor Foundation (to A.A.-B. and D.H.R.), National Institutes of Health (NS28478, to A.A.-B. P01NS083513, to D.H.R. and A.A-B.; NRSA 1F32NS067889-01A1, to M.C.T.), Howard Hughes Medical Institute (to D.H.R.), and John G. Bowes Research Fund (to A.A.-B.) R.A.L. is supported by the UCSF Medical Scientist Training Program, Neuroscience Graduate Program, and Discovery Fellows Program. L.C.F. is a Howard Hughes Medical Institute fellow of the Helen Hay Whitney Foundation. M.C.T. was supported by the UCSF Neurological Surgery Residency Program. A.A.-B. is the Heather and Melanie Muss Endowed Chair and Professor of Neurosurgery.

\section{Author contributions}

R.A.L., M.C.T., D.H.R. and A.A.-B. conceived the study. R.A.L., L.C.F., M.C.T., D.H.R and A.A-B. designed experiments. R.A.L., C.G., J.L.R.-R., L.C.F. and M.C.T. performed experiments. R.A.L. and A.A.-B. analysed the results and wrote the manuscript. All authors reviewed and helped edit the manuscript.

\section{Additional information}

Supplementary Information accompanies this paper at http://www.nature.com/ naturecommunications

Competing financial interests: The authors declare no competing financial interests.

Reprints and permission information is available online at http://npg.nature.com/ reprintsandpermissions/

How to cite this article: Lindquist, R. A. et al. Identification of proliferative progenitors associated with prominent postnatal growth of the pons. Nat. Commun. 7:11628 doi: $10.1038 /$ ncomms 11628 (2016)

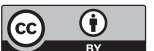

This work is licensed under a Creative Commons Attribution 4.0 International License. The images or other third party material in this article are included in the article's Creative Commons license, unless indicated otherwise in the credit line; if the material is not included under the Creative Commons license, users will need to obtain permission from the license holder to reproduce the material. To view a copy of this license, visit http://creativecommons.org/licenses/by/4.0/ 